\title{
ENVIRONMENTAL TEST PROGRAM FOR THE MARS EXPLORATION ROVER PROJECT
}

\author{
Terry C. Fisher ${ }^{(1),}$ Paul L. Van Velzer ${ }^{(2)}$ \\ Jet Propulsion Laboratory, California Institute of Technology \\ 4800 Oak Grove Drive, Pasadena, CA 91109 USA \\ ${ }^{(1)}$ Email: Terry.C.Fisher@jpl.nasa.gov, ${ }^{(2)}$ Email: Paul.L.Vanvelzer@jpl.nasa.gov
}

\begin{abstract}
On June 10 and July 7, 2003 the National Aeronautics and Space Administration (NASA) launched two spacecraft from Cape Canaveral, Florida for a six (6) months flight to the Red Planet, Mars. The two Mars Exploration Rover spacecraft landed safely on the planet in January 2004.

Prior to the successful launch, both of the spacecraft were involved in a comprehensive test campaign that included development, qualification, and protoflight test programs. Testing was performed to simulate the environments associated with launch, inter-planetary cruise, landing on the planet and Mars surface operations.

Unique test requirements included operating the spacecraft while the chamber pressure was controlled to simulate the decent to the planet from deep space, high impact landing loads and rover operations on the surface of the planet at 8 Torr and $-130^{\circ} \mathrm{C}$.

This paper will present an overview of the test program that included vibration, pyro-shock, landing loads, acoustic noise, thermal vacuum and solar simulation testing at the Jet Propulsion Laboratory (JPL) Environmental Test Laboratory facilities in Pasadena, California.
\end{abstract}

\section{INTRODUCTION}

The National Aeronautics and Space Administration's (NASA's) twin robot geologists, the Mars Exploration Rovers, were launched toward Mars in 2003 in search of answers about the history of water on Mars. The first rover, named "Spirit", landed safely on the surface of Mars on January 3, 2004. The second rover, named "Opportunity", landed safely on January 24, 2004.

The Mars Exploration Rover (MER) mission is part of NASA's Mars Exploration Program, a long-term effort of robotic exploration of the red planet. The program seeks to take advantage of each launch opportunity to go to Mars. Primary among the mission's scientific goals is to search for and characterize a wide range of rocks and soils that hold clues to past water activity on Mars. The spacecraft were targeted to sites that appear to have been affected by liquid water in the past.

The mission scenario is that after the airbag protected landing, the spacecraft will settle onto the surface and open, the rovers will roll out to take panoramic images. These images will give scientists the information they need to select promising geological targets that will tell part of the story of water in Mars' past. Then, the rovers will drive (Fig. 1.) to those locations to perform onsite scientific investigations over the course of their nominal 90-day mission. 


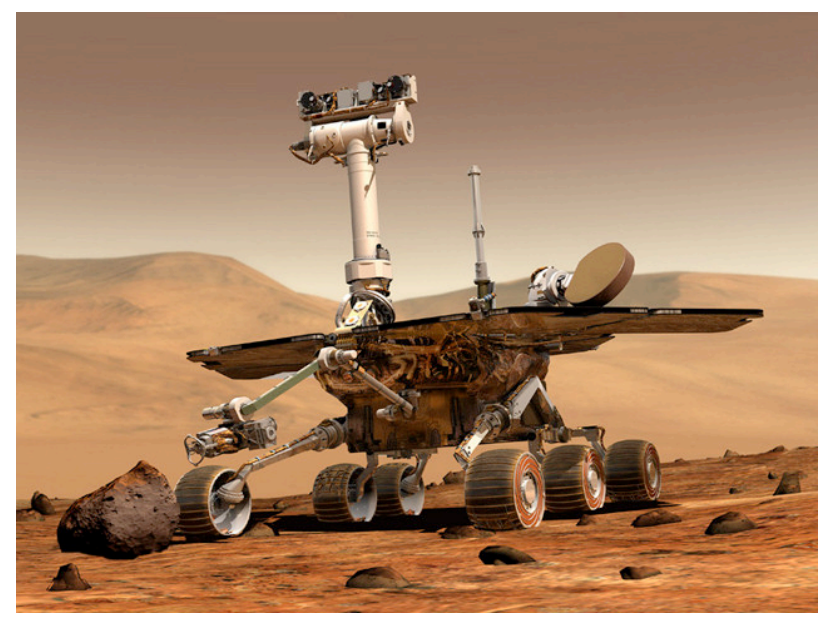

Fig. 1. Rover on Martian Surface

In order to carry out their assigned mission to Mars, the twin spacecraft were subjected to a comprehensive test program at the Jet Propulsion Laboratory (JPL). The test program included vibration and acoustic noise testing to simulate the launch environment, spin-balance to simulate separation from the launch vehicle, solar-thermal-vacuum testing to simulate the inter-planetary cruise phase of the mission, pressure variation testing to simulate the decent to the Martian atmosphere from deep space, high level shock to simulate the bouncing landing in the air bags, pyro-shock to simulate the deployment of the solar arrays and mobility components and finally thermal-vacuum and thermal cycle testing to simulate the harsh environment of the planet's surface.

\section{SPACECRAFT CONFIGURATION}

The Mars Exploration Rover flight system or spacecraft is comprised of the Cruise Stage, the Entry, Descent, and Landing System and the Rover.

The Cruise Stage (Fig. 2.), which is the configuration for launch and travel between Earth and Mars has a mass in excess of 1,060 kilograms (2,300 pounds) and is approximately 2.65 meters ( 8.7 feet) in diameter and 1.6 meters (5.2 feet) high.

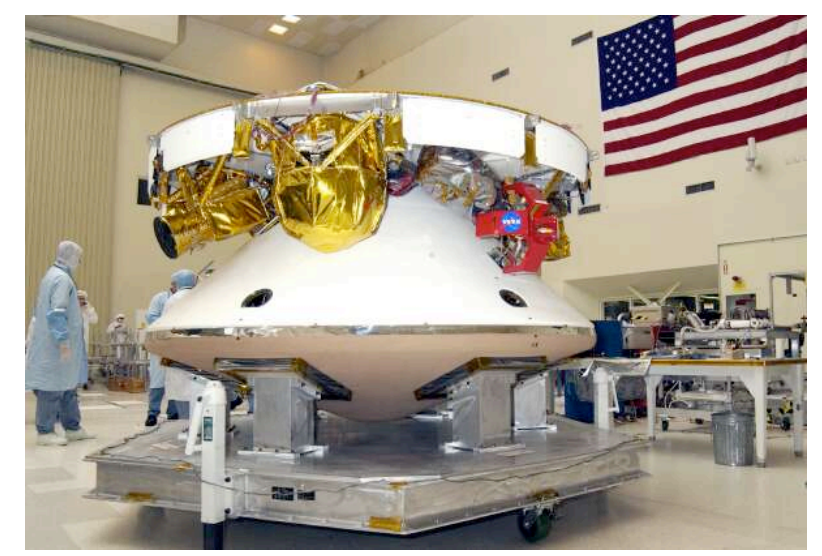

Fig. 2. MER Cruise Stage 
The Entry, Descent, and Landing System configuration is used for the entry into the Martian Atmosphere and landing on the surface of Mars. The system includes the heatshield and backshell, retro rockets, the parachute, the airbags and lander structure.

The Rover is the heart of the flight system. All navigation, propulsion, mobility, power, and communication are controlled via the electronic systems contained in the Rover. The Rover is a wheeled vehicle that carries the science instruments to different points of interest on the planet. The instruments on the Rover include imagers, spectrometers, and the Rock Abrasion Tool. The imagers are the Panoramic Cameras, Hazard Avoidance Cameras, Navigation Cameras, and the Microscopic Imager. The spectrometers are the Miniature Thermal Emissions Spectrometer, Mossbauer Spectrometer, and Alpha Particle X-Ray Spectrometer. These science and engineering instruments are state-of-the-art tools that will acquire important science information that will help characterize a wide range of rocks and soils that hold clues to past water activity on Mars.

\section{OVERVIEW OF THE MER ENVIRONMENTAL TEST PROGRAM}

The majority of the environmental testing for the MER project was performed in the JPL Environmental Test Laboratory (ETL) in Pasadena, California. Testing in the ETL included development and flight qualification environmental tests at the component, assembly, sub-system, and system levels. Environmental tests included thermal, thermal cycle, thermal-vacuum, solarthermal-vacuum, vibration, shock, landing loads and acoustic noise.

The hardware had to be subjected to a test program that would simulate the temperature extremes of the Martian surface and since the MER landler was to be much more massive than the successful Mars Pathfinder Rover (Fig. 3.) which landed on Mars in 1997, a developmental test program was started in the early stages of the MER project to design and qualify components to survive the landing environment on Mars. Numerous vibration, sine-pulse and sine-burst tests were performed on development hardware prior to the fabrication of the flight systems. Flight system testing included vibration, acoustic and thermal-vacuum tests of both rovers and the 2 flight spacecraft.

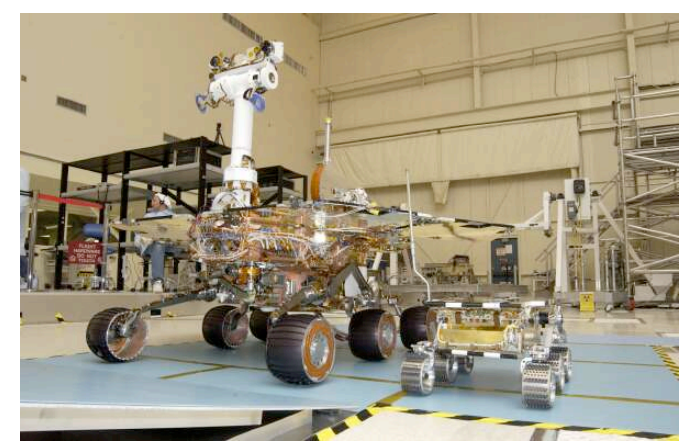

Fig. 3. Size comparison of the 1997 and the 2003 Mars Rovers 
Additional environmental testing was carried out at other facilities like NASA's Glenn Plumbrook Station where the air bags were subjected to drop tests in the very large Space Power Facility vacuum chamber and landing loads testing at National Technical Systems (NTS) centrifuge facility in Southern California. Many of the electronic sub-systems such as the UHF radio and the radar altimeter had thermal-vacuum and vibration testing performed at the manufacturer's facilities prior to integration into the flight system at JPL.

Because of the large amount of developmental, qualification and protoflight testing and retesting required during a very short time frame, the efficient and maximum utilization of test facilities was very important. To help accomplish this very aggressive test program, the ETL maintained close contact with project's management through the use of weekly test scheduling and status meetings. The use of off-site vibration test facilities at Northrop Grumman Space Systems (formerly TRW), and Northrop Grumman Electronic Systems (formerly Aerojet) helped relieve the workload on the JPL Environmental Test Lab.

\section{JPL ENVIRONMENTAL TEST FACILITIES}

The Environmental Test Lab at JPL is comprised of numerous horizontal thermal-vacuum chambers of various sizes ranging from 0.9 meter $(3 \mathrm{feet})$ to 3 meters ( 10 feet) in diameter by 1 meter ( 3.3 feet) to 4.3 meters ( 14 feet) in length. These chambers are capable of high vacuum levels of $10^{-6}$ Torr with a temperature range of $+125^{\circ} \mathrm{C}$ to $-185^{\circ} \mathrm{C}$. These chambers were used for component, assembly, and sub-system level thermal vacuum testing of the various MER hardware. The ETL also has two large vertical thermal-vacuum chambers. The smaller chamber is referred to as the 10-ft Space Simulator Facility and is 3.0 meters (10 feet) in diameter and 13.7 meters (45 feet) tall. This facility was used extensively for the Martian surface testing of the two rovers. This chamber is capable of high vacuum operations, but for this test program the majority of the testing was conducted at the Mars surface pressure of approximately 8 Torr (10 millibar).

The largest chamber at JPL is the 25-ft Space Simulator Facility in Building 150 (Fig. 4.). This chamber is 7.6 meters ( 25 feet) in diameter and 25.7 meters ( 85 feet) high. In addition to high vacuum and a temperature control range of $-185^{\circ} \mathrm{C}$ to $+150^{\circ} \mathrm{C}$, this chamber has solar simulation capabilities. The solar simulator can produce a well-collimated 5.8-meter (19 feet) diameter light beam with intensities of up to 2.3 solar constants and a uniformity of $+/-4 \%$. This chamber was used for MER interplanetary cruise testing.

The dynamics testing area of the ETL is comprised of four electro-dynamic vibration systems of various capabilities and an acoustic noise chamber. The shakers range in size from 20,000 force-pounds $(90 \mathrm{kN})$ to 58,000 force-pounds $(265 \mathrm{kN})$. Redundant digital control systems and $210 \mathrm{~kW}$ power amplifiers control the shakers. The acoustic noise chamber has a volume of 10,900 cubic-feet (310 cubic-meters) and can obtain sound pressure levels of $155 \mathrm{db}$.

The ETL has three large class 10,000 (ISO 7) clean rooms that are adjacent to the acoustic chamber and both space simulator facilities. 
Data acquisition and recording in the ETL is provided by state-of-the-art digital data systems. In the thermal-vacuum test areas data is collected via a 1000 channel high speed system that records thermocouple output, voltage, current and pressure data from various transducers on the unit under test and from the facility. Dynamic test data of up to 200 channels is recorded and analyzed either by the control system or on various digital recorders.

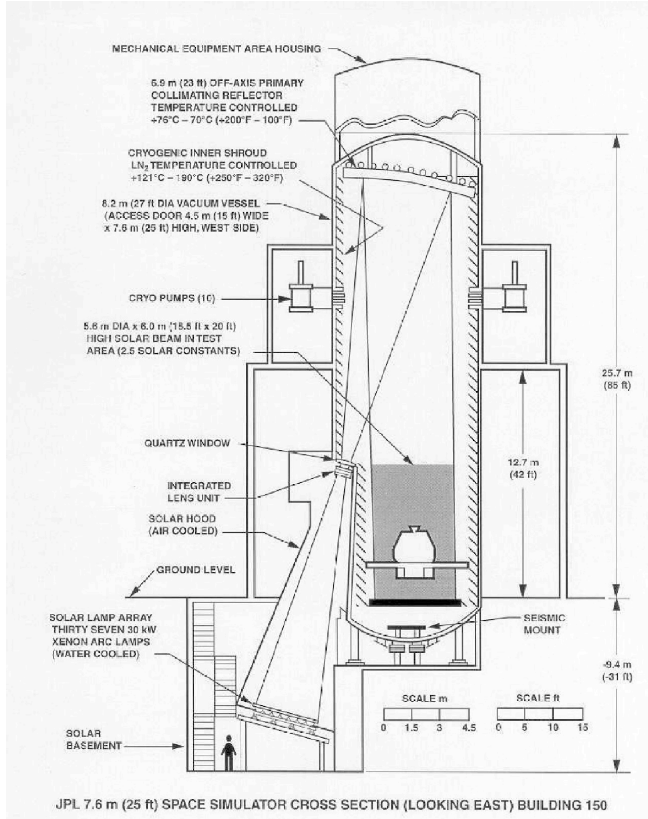

Fig. 4. 25-ft Space Simulator

\section{MER DYNAMICS TEST PROGRAM}

During the early design stages of the MER test program, numerous tests were performed on engineering models of various structural elements and mobility components of the rover and lander to verify they would survive the landing shock loads associated with the landing on Mars. Testing was performed both on vibration tables and on a large centrifuge.

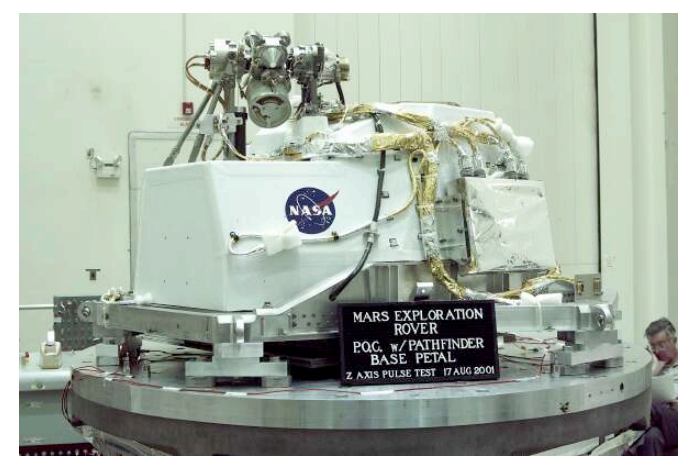

Fig. 5. Rover Landing Loads Test

Also during the design phase of the project many vibration and shock tests were performed on the small electric motors, actuators and relays that are used to deploy the many mechanisms on the rover. 
During the flight acceptance test phase of the project, numerous assemblies and subsystems were tested in random vibration environments. Units such as antennas, mobility components, mechanisms, electronic chassis, cameras, and spectrometers were tested in the ETL and at off-site test facilities. Random vibration testing was performed in all three axes at levels of 5.5 to 8.0 Grms, depending on the requirements of each individual unit under test.

During the assembly, integration and test phase of the project, the flight systems were involved in various dynamic protoflight tests. Vibration and acoustic testing was performed in October 2002 (Fig. 6.) and January 2003 on the two flight spacecraft with the rover stowed inside the aero shell in the launch configuration. In addition the flight rovers were subjected to vibration tests individually.

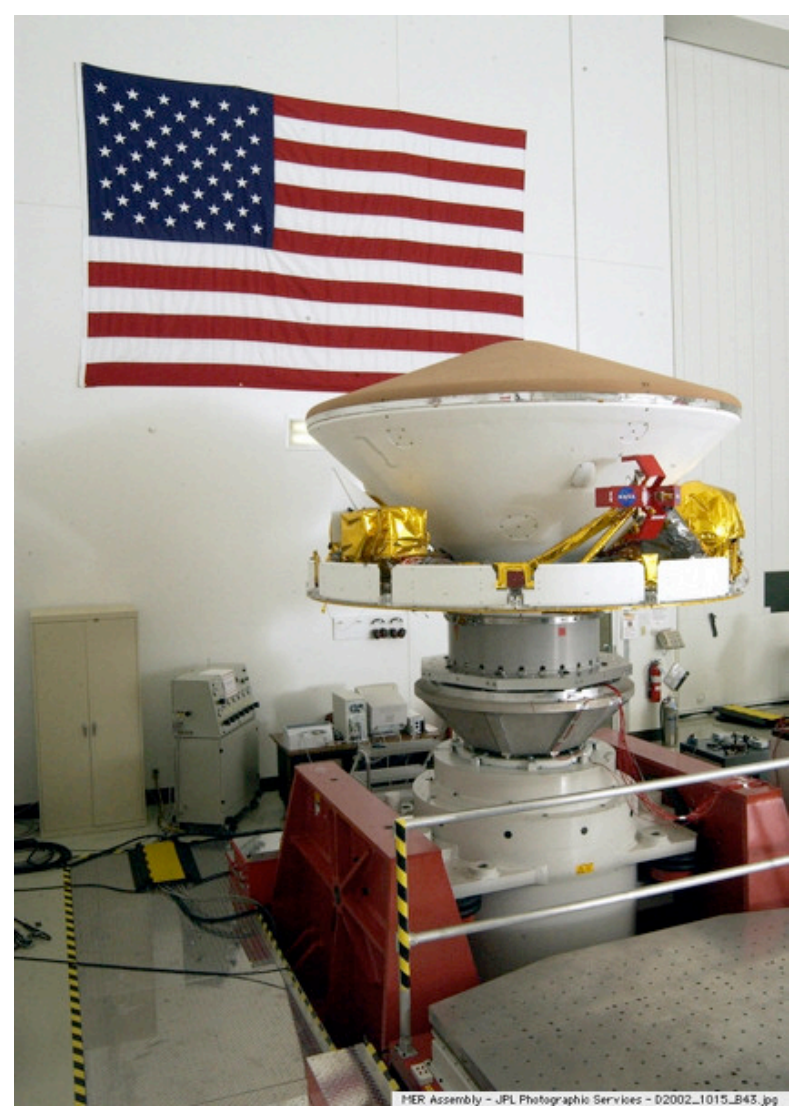

Fig. 6. MER Flight Spacecraft Vibration Test

Acoustic testing of the full flight systems were performed at $145 \mathrm{db}$ in the JPL Acoustic Noise test chamber (Fig. 7.). The acoustic chamber is located in the same clean room that contains the large 994-vibration system.

After the completion of vibration and acoustic testing, just prior to system level thermal vacuum testing, the flight spacecraft were mounted on a spin-balance machine to obtain center of gravity and moment of inertia data for the project's structural dynamics engineers. Personnel from Lockheed-Martin, using the same equipment that would be used at Cape Canaveral prior to launch, performed the spin balance testing at JPL. 


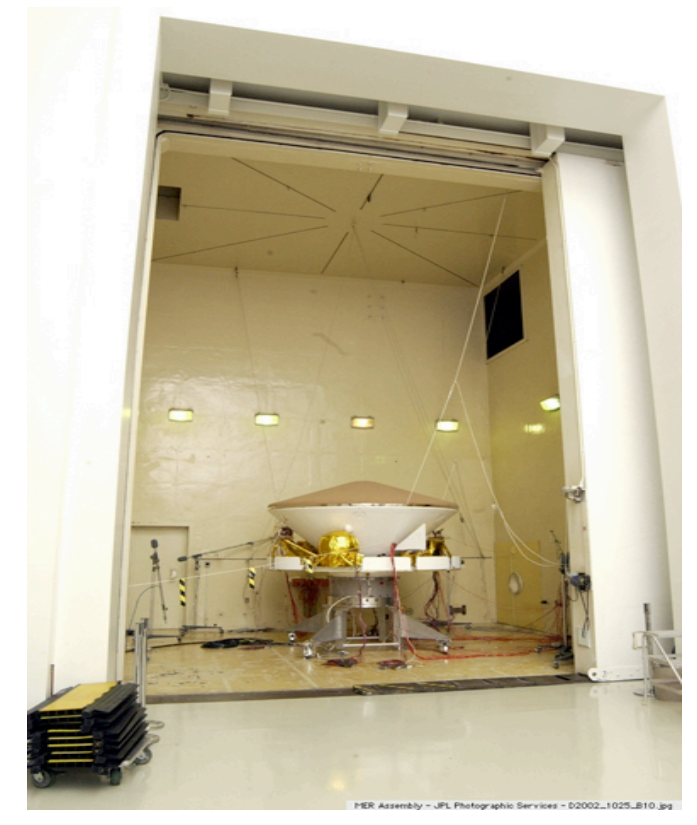

Fig. 7. MER Flight Spacecraft Acoustic Noise Test

\section{MER THERMAL-VACUUM TEST PROGRAM}

During the design phase of the MER project many thermal cycle and thermal vacuum tests were performed on the small electric motors, actuators and relays that are used to deploy the many mechanisms on the rover. Much of this component level testing was performed at the Mars surface pressure of approximately 8 Torr (10 millibar) in a nitrogen or occasionally a carbon dioxide $\left(\mathrm{CO}_{2}\right)$ environment.

During the flight acceptance test phase of the project, numerous assemblies and subsystems were tested in thermal cycle and thermal vacuum chambers in the ETL. Units such as mobility components, actuators, mechanisms, electronic packages, cameras and spectrometers under went thermal vacuum and thermal cycle testing. Also, countless thermal vacuum contamination control and planetary protection bake-outs were performed on flight thermal blankets, cable harnesses, mechanical components and electronic assemblies. A typical thermal blanket bake-out was performed at $110^{\circ} \mathrm{C}$ for 50 hours under high vacuum conditions.

During the assembly, integration and test phase of the project the two flight spacecraft were tested individually in a solar-thermal-vacuum environment in the JPL large space simulation chamber (Fig. 8.). The first spacecraft was tested in November 2002 and the second spacecraft was tested in January 2003. Testing was performed at various temperature and solar levels to simulate the worst-case hot and cold extremes to be encountered during the six (6) months cruise from Earth to Mars.

These 10 days of continuous testing were performed at high vacuum levels ( $10^{-6}$ Torr range) to simulate the pressure of deep space. During these tests the chamber walls were maintained at liquid nitrogen temperatures of $-185^{\circ} \mathrm{C}$. Solar simulation was controlled at both 1 Earth Solar Constant $\left(130 \mathrm{mw} / \mathrm{cm}^{2}\right)$ and near Mars solar levels of $60 \mathrm{mw} / \mathrm{cm}^{2}$. There were 3 thruster firing tests during space simulator testing and the chamber pumping system was able to maintain a pressure of less than $3.5 \times 10^{-4}$ Torr. 


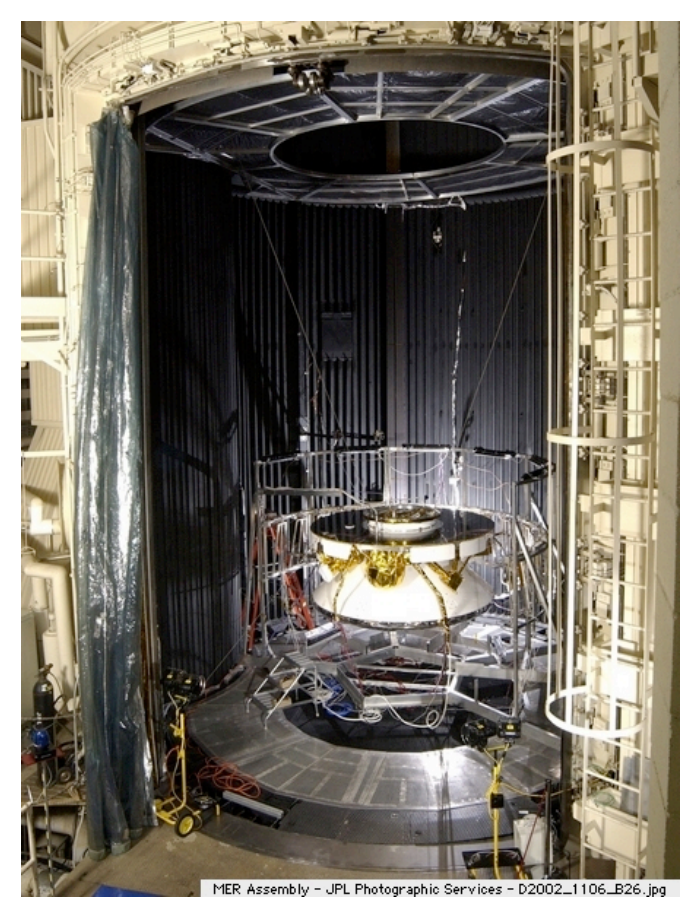

Fig. 8. System Level Solar-Thermal-Vacuum Test in the 25-ft Space Simulator Facility

A special test was performed for the telecommunications system to simulate the decent into the Martian atmosphere. There were concerns in the project office regarding the ability to communicate with the spacecraft during the decent phase of the mission because of the changing pressure. This type of "controlled re-pressurization or backfill" had never been attempted in the JPL large space simulator. To accomplish this special test, the chamber backfill with nitrogen was halted at $1 \times 10^{-1}$ Torr and then resumed at an accurately controlled rate to reach 8 Torr in 6 minutes. This testing confirmed that the telecommunications system would work properly during the decent phase of the mission.

Additional system level thermal vacuum testing was performed during the period from December 2002 through April 2003 on the two rovers in the JPL 10-ft Space Simulator. This testing consisted of the rovers in the landed configuration in a Mars environment. (Fig. 9.)

Chamber pressure was maintained with nitrogen in the 8 to 10 Torr range while the temperature of the shrouds and ground plate were held at various levels between $+20^{\circ} \mathrm{C}$ and $-130^{\circ} \mathrm{C}$ to simulate Martian day and night thermal extremes.

During one of these tests numerous pyrotechnic devices were fired to verify the deployment of solar arrays and mobility components. Additionally, the Rover was placed at several different angles in relation to the ground plate to simulate different landing positions on the Martian surface to verify that the Rover could properly deploy under these adverse conditions. 


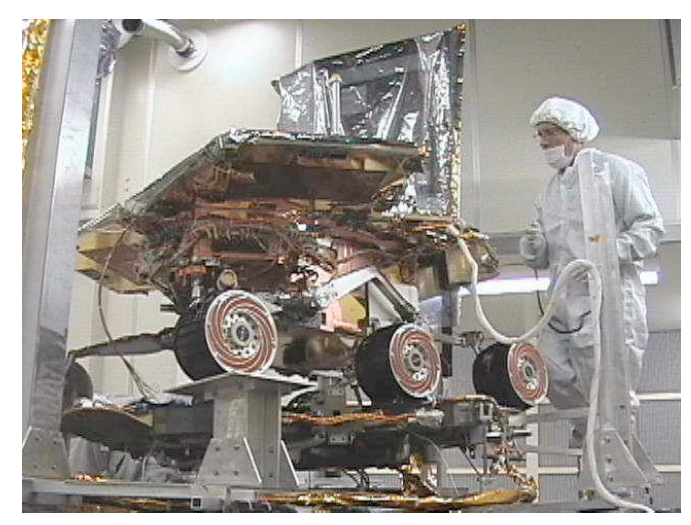

Fig. 9. Rover in 10-ft Space Simulator

\section{CONCLUSIONS}

The Mars Exploration Rover test program was successfully performed in the JPL Environmental Test Laboratory between early 2001 and the spring of 2003 . Close contact with the project management and the project's engineering staff helped in maintaining a smooth flow of testing through the ETL. At the completion of the environmental test program, the two flight worthy spacecraft were successfully launched in the summer of 2003.

\section{ACKNOWLEDGEMENT}

The work described in this paper was carried out at the Jet Propulsion Laboratory for the California Institute of Technology, under a contract with the National Aeronautics and Space Administration.

\section{REFERENCES}

1. MER 2 Rover Summary Test Report, Thermal Vacuum Test, JPL Environmental Test Laboratory Report Number 101203

(Internal JPL Document)

2. MER Spacecraft Summary Test Report, Acoustic Noise Test, JPL Environmental Test Laboratory Report Number 101221

(Internal JPL Document)

3. MER 1 Spacecraft - Summary Test Report, System Thermal Test, JPL Environmental Test Laboratory Report Number 101171

(Internal JPL Document)

4. Mars Exploration Rover web site http://mars.jpl.nasa.gov/mer/overview/

5. Man K.F., Farguson C.T, and Hoffman A.R., Mars Exploration Rover (MER) Project Environmental Assurance Program, $5^{\text {th }}$ International Symposium on Environmental Testing for Space Programmes, June 2004. 


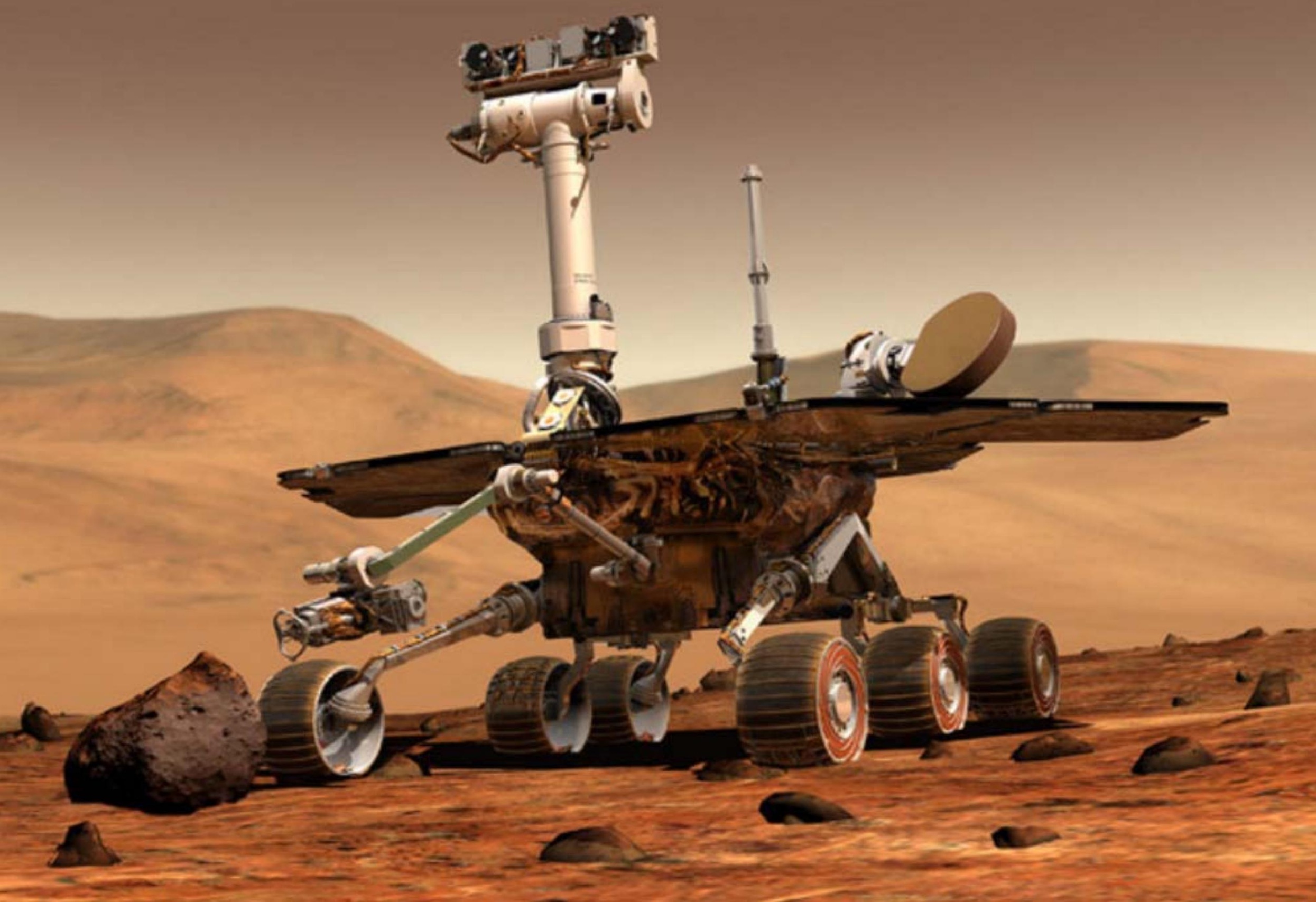




\section{Environmental Test Program for the Mars Exploration Rover Project}

\section{Terry C. Fisher Paul L. Van Velzer}

$23^{\text {rd }}$ Space Simulation Conference Annapolis Maryland

November 2004 


\section{Topics}

- Mars Exploration Program Overview

- Environmental Test Program and Test Facilities

- Vibration

- Acoustic

- Solar-Thermal-Vacuum 


\section{NASA's Mars Exploration Program JPL}

- The Mars Exploration Rover (MER) mission is part of NASA's Mars Exploration Program, a long-term effort of robotic exploration of the red planet. The program seeks to take advantage of each launch opportunity to go to Mars

- Primary among the mission's scientific goals is to search for and characterize a wide range of rocks and soils that hold clues to past water activity on Mars. The MER spacecraft were targeted to sites that appear to have been affected by liquid water in the past 


\section{Mars Exploration Program \\ JPL}

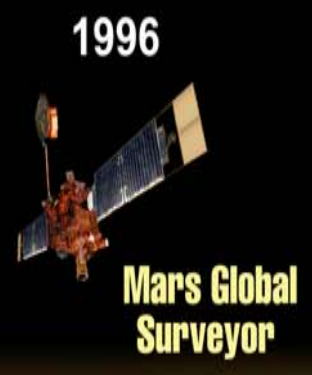

Mars Pathininder

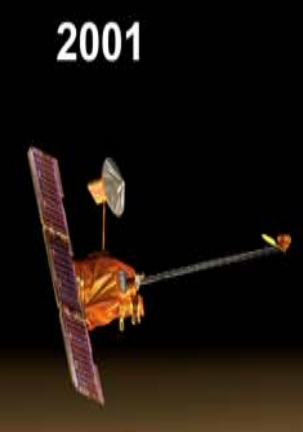

Mars Odyssey

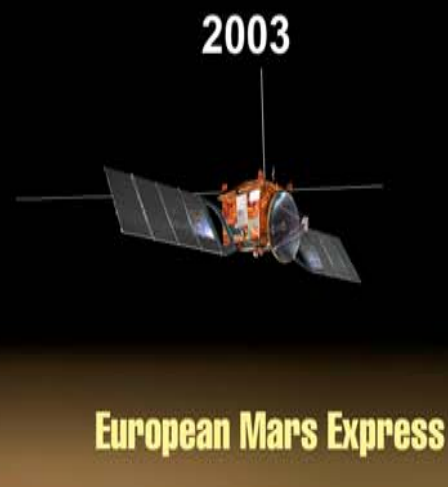

Mars

Es Exploration Rorers

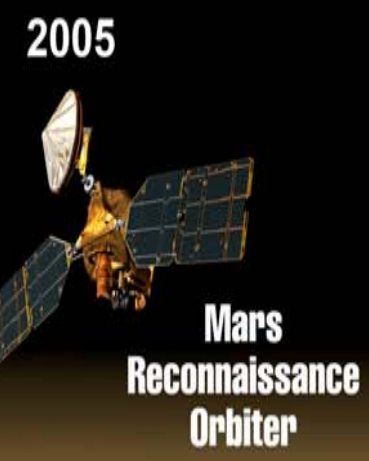

Phoenix Seout
2007

2009

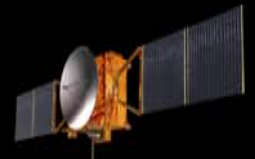

Mars

Telecom Onhiter

Mars

Seience Lahoratory

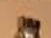




\section{Mars Exploration Program: \\ Search for Past Life}

2011

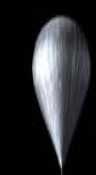

in

Mars Seout

$x$
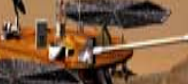

तो

2016

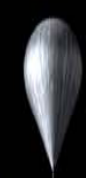

2018

Astroliology Field Lalioratory

or

Deen Drill
2020

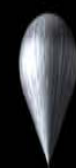

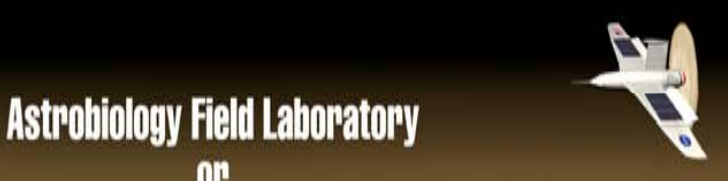

Mars Sample Mars Scout Return

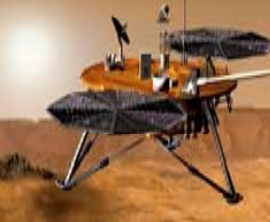




\section{Mars Exploration Rover Project JPL}

- NASA's twin robot geologists, the Mars Exploration Rovers, were launched to Mars in 2003 in search of answers about the history of water on Mars. The first rover, named "Spirit", landed safely on the surface of Mars on January 3, 2004. The second rover, named "Opportunity", landed safely on January 24, 2004

- The Mars Exploration Rover (MER) flight system or spacecraft is comprised of the Cruise Stage, the Entry, Descent, and Landing System and the Rover 


\section{Launch and Separation JPL}
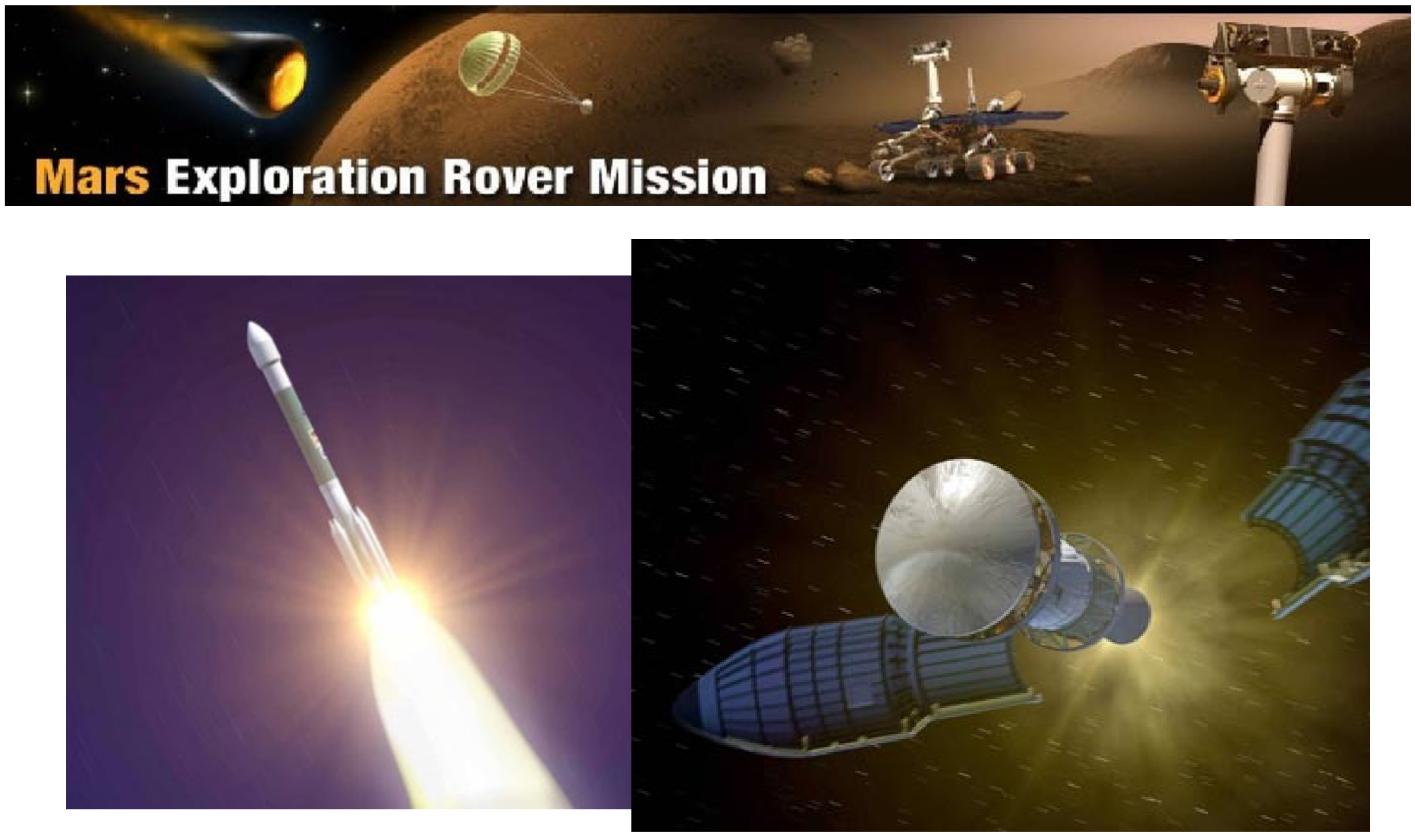


\section{Decent and Landing $\quad J P L$}
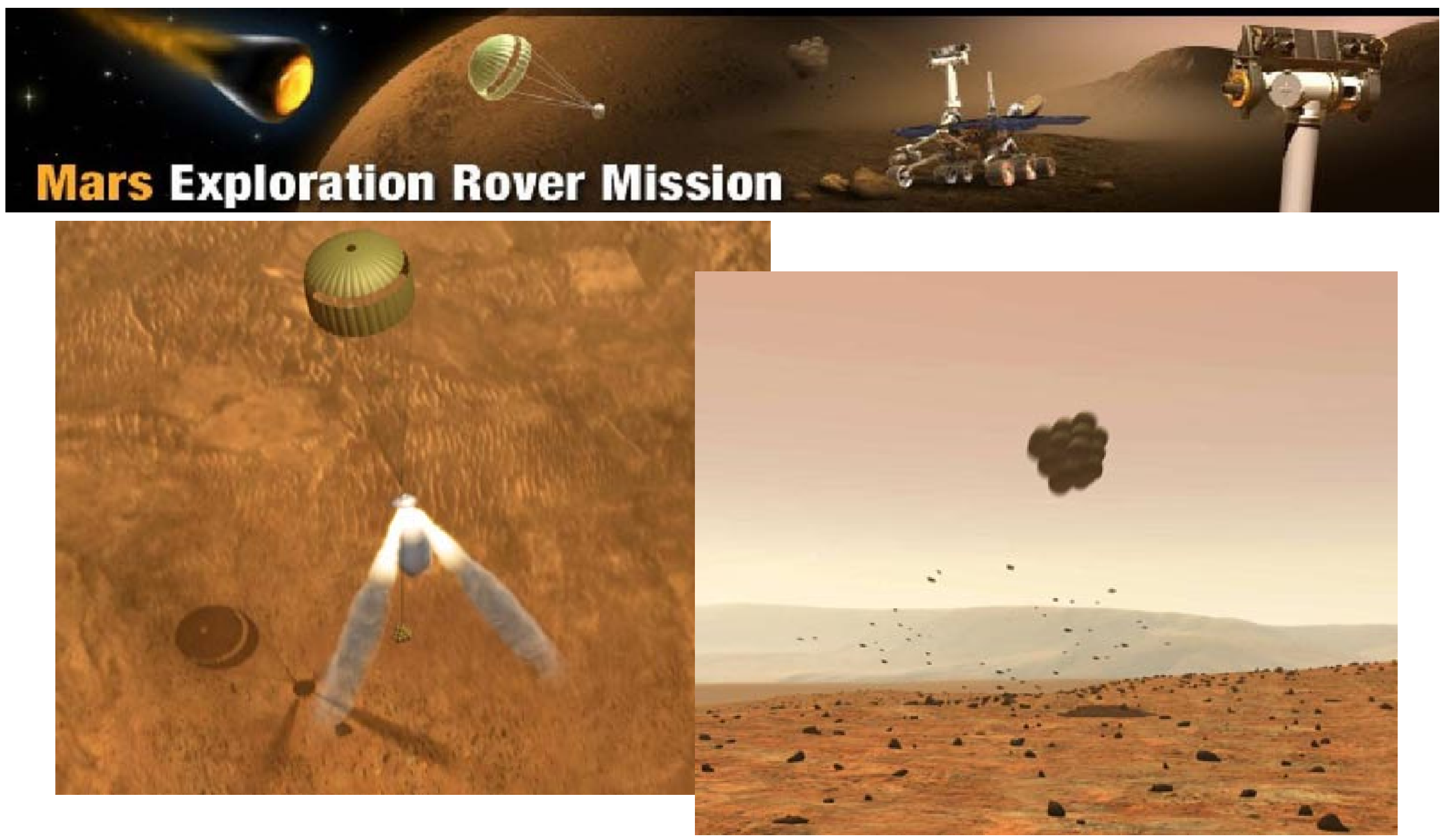


\section{Mars Exploration Rover Project JPL}

- In order to carry out their assigned mission to Mars, the twin spacecraft were subjected to a comprehensive test program at the Jet Propulsion Laboratory

- The environmental test program included:

- Vibration

- Landing loads

- Solar-Thermal-Vacuum

- Pressure variation testing to simulate the decent to the Martian atmosphere from deep space

- Pyro-shock

- Thermal-Vacuum testing to simulate the harsh environment of the planet's surface 


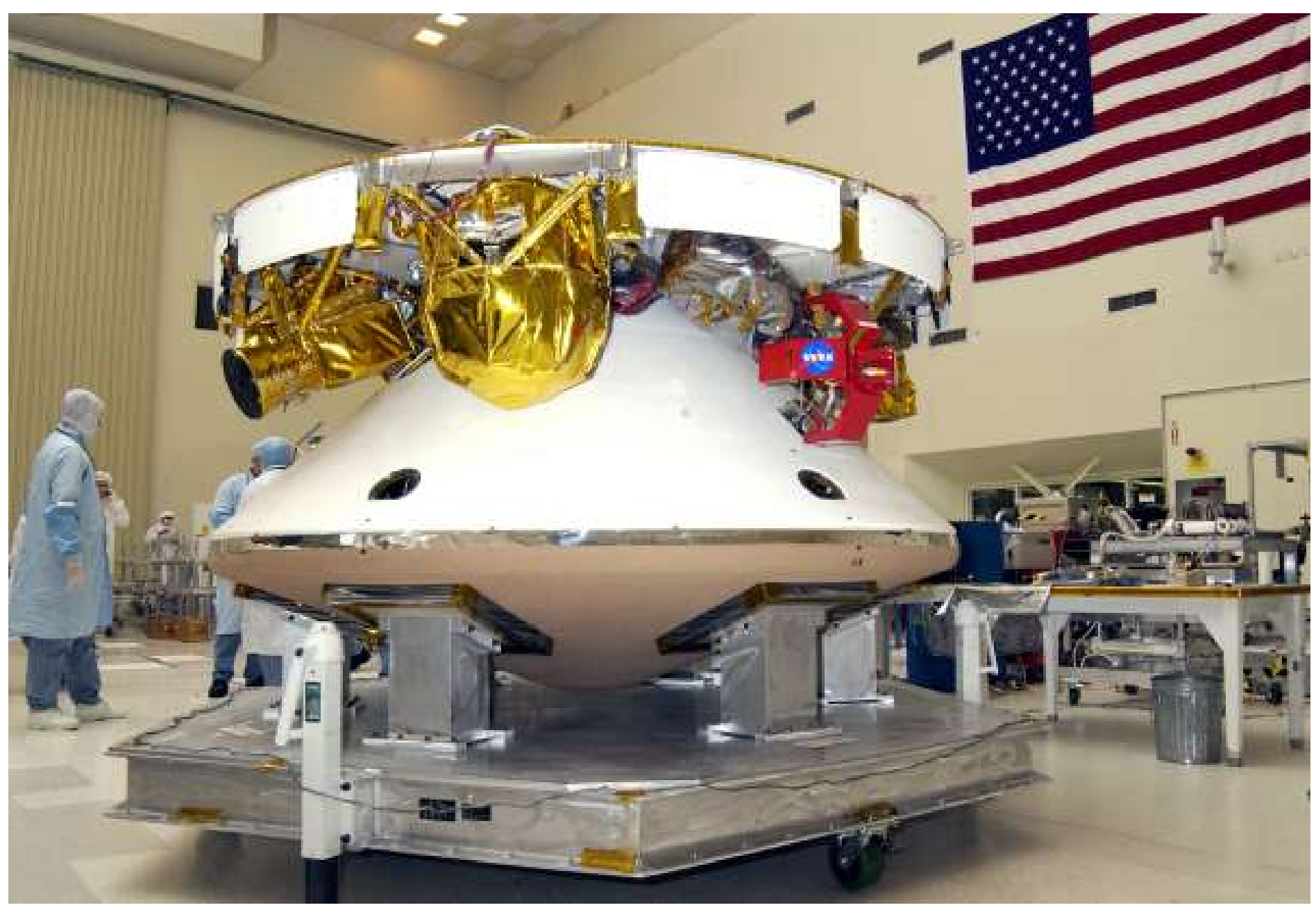




\section{Rover in fully deployed configuration on Mars}

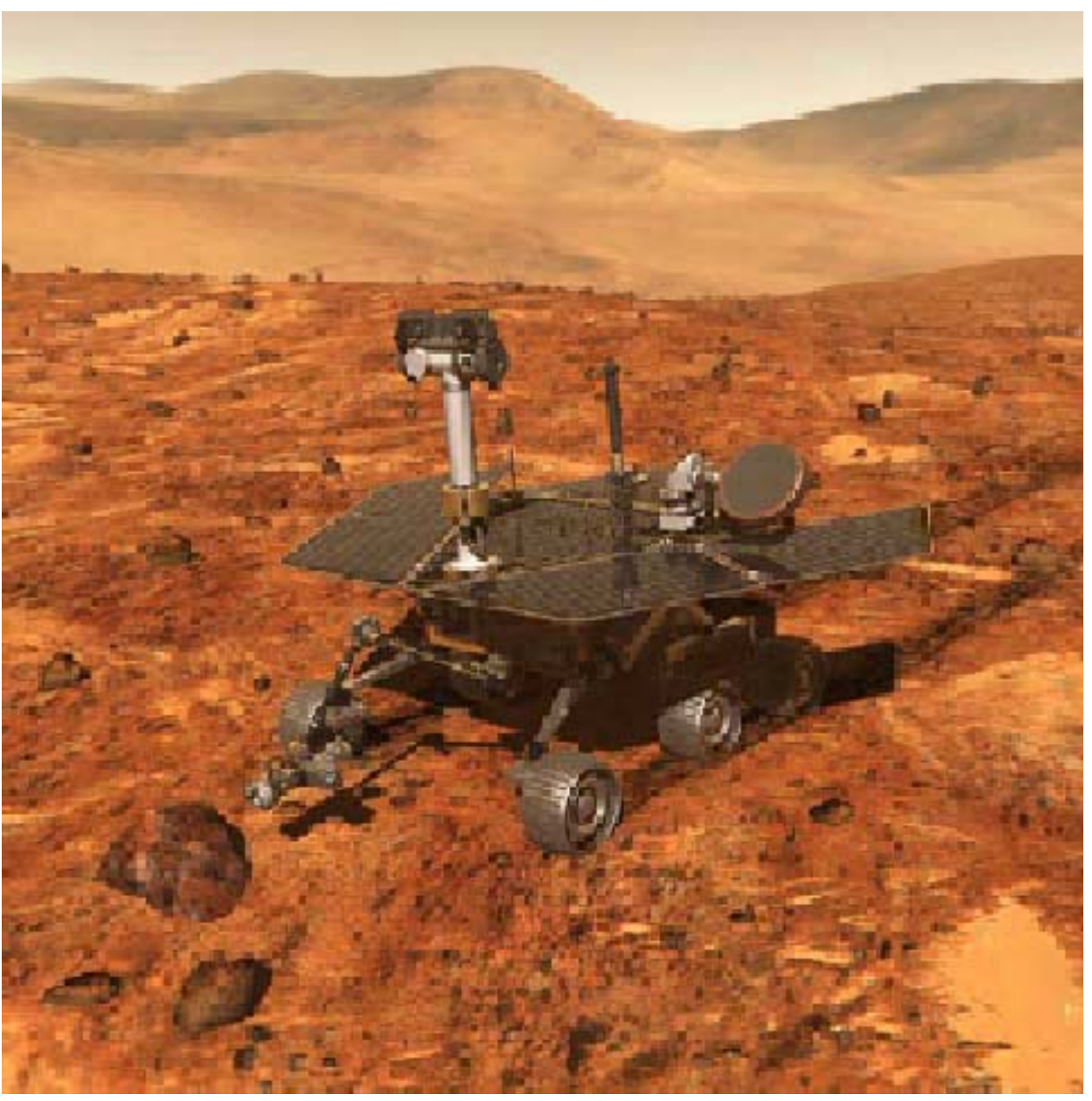




\section{MER Imaging System}

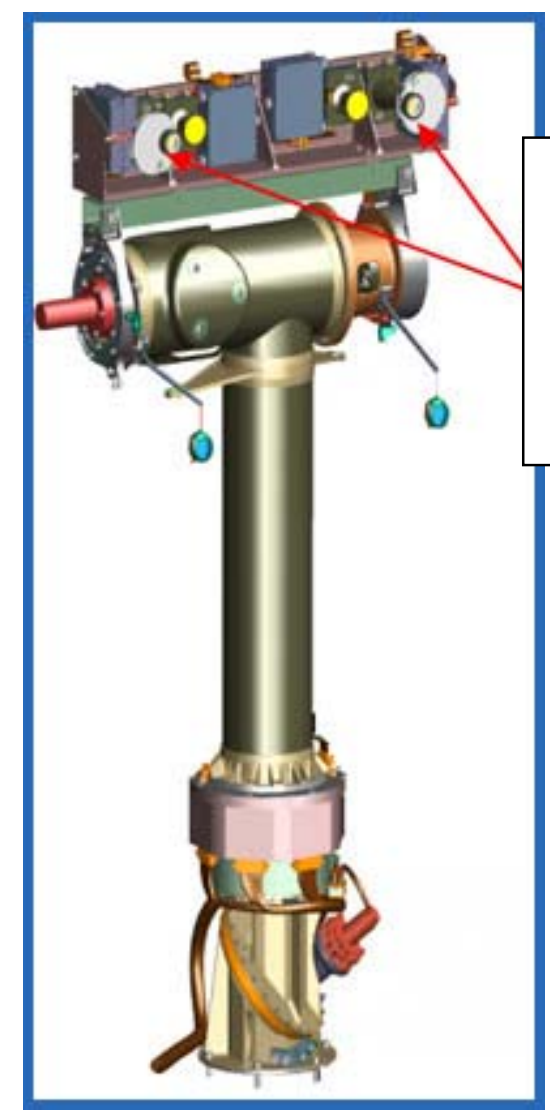

- MER Panoramic Cameras and the Pan Cam Mast

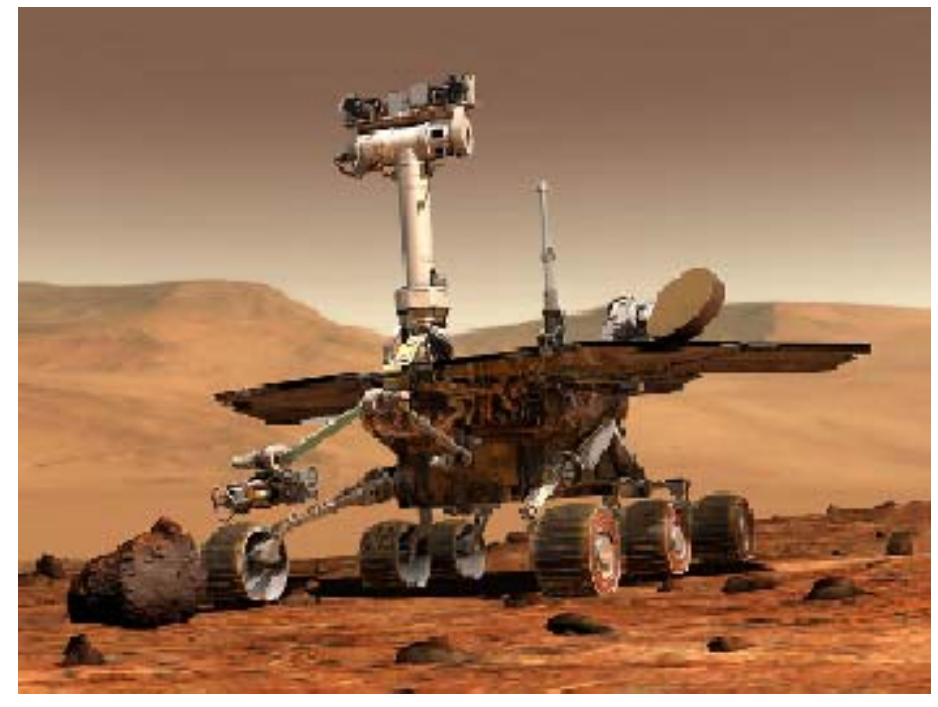

Rover with deployed

Pan Cam mast 
Size comparison of 1997 Mars Pathfinder and the 2003 Mars Exploration Rover

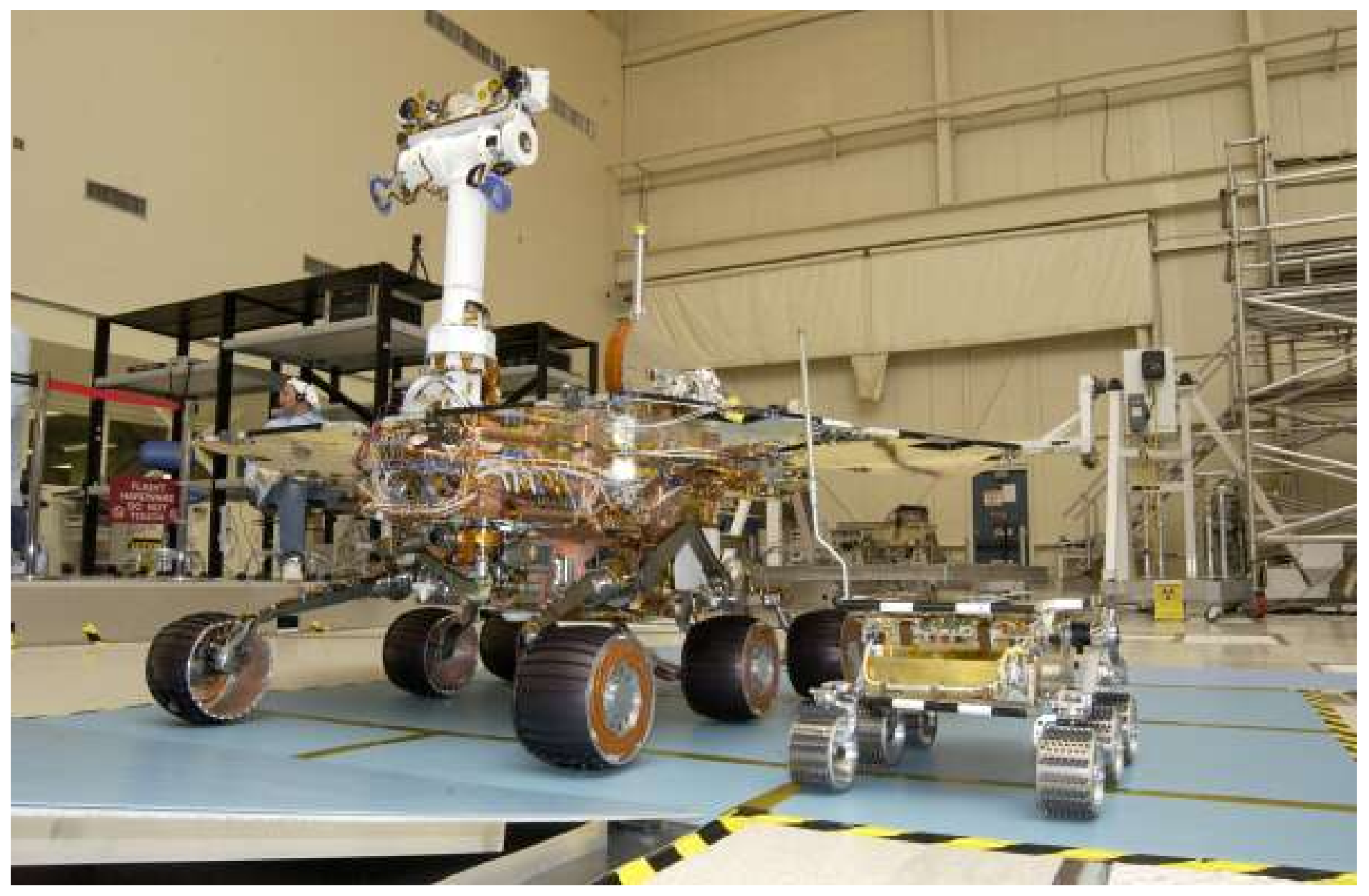




\section{NASA \\ Size comparison of 1997 Mars Pathfinder and the 2003 Mars Exploration Rover

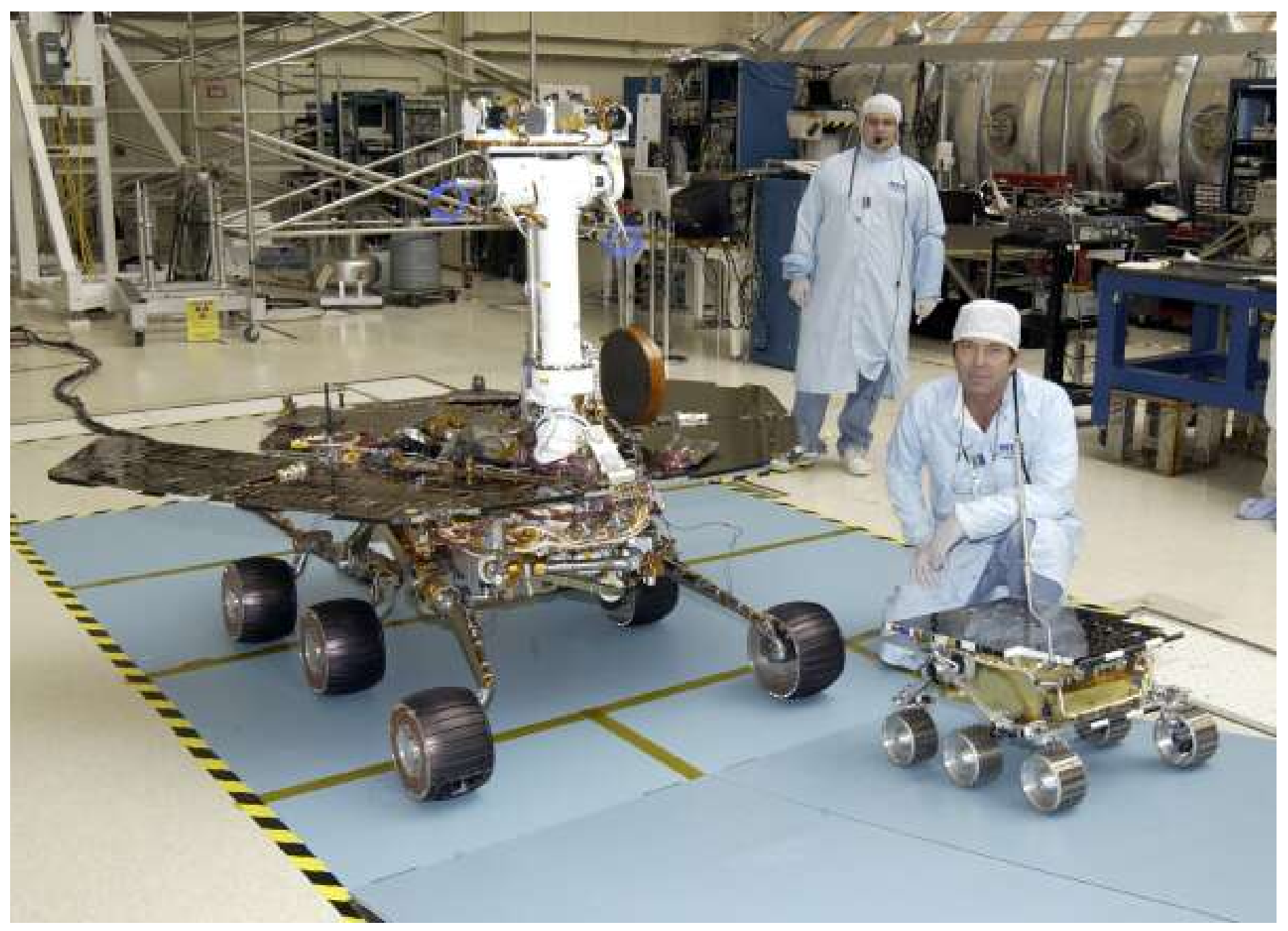




\section{Dynamics Test Program}

- Development Testing

- Landing Loads and Pyro-shock

- Sub-system Testing

- Random Vibration

- 5.5 to $8.0 \mathrm{~g}$ RMS

- System Level Testing

- Random Vibration for Flight System

- Random Vibration and Landing Loads for Rover

- Acoustic Testing of Flight System

- $145 \mathrm{db}$ 


\section{Vibration Test JPL}

- MER Flight Spacecraft in preparation for random vibration testing in the vertical axis on the LDS 994 shaker

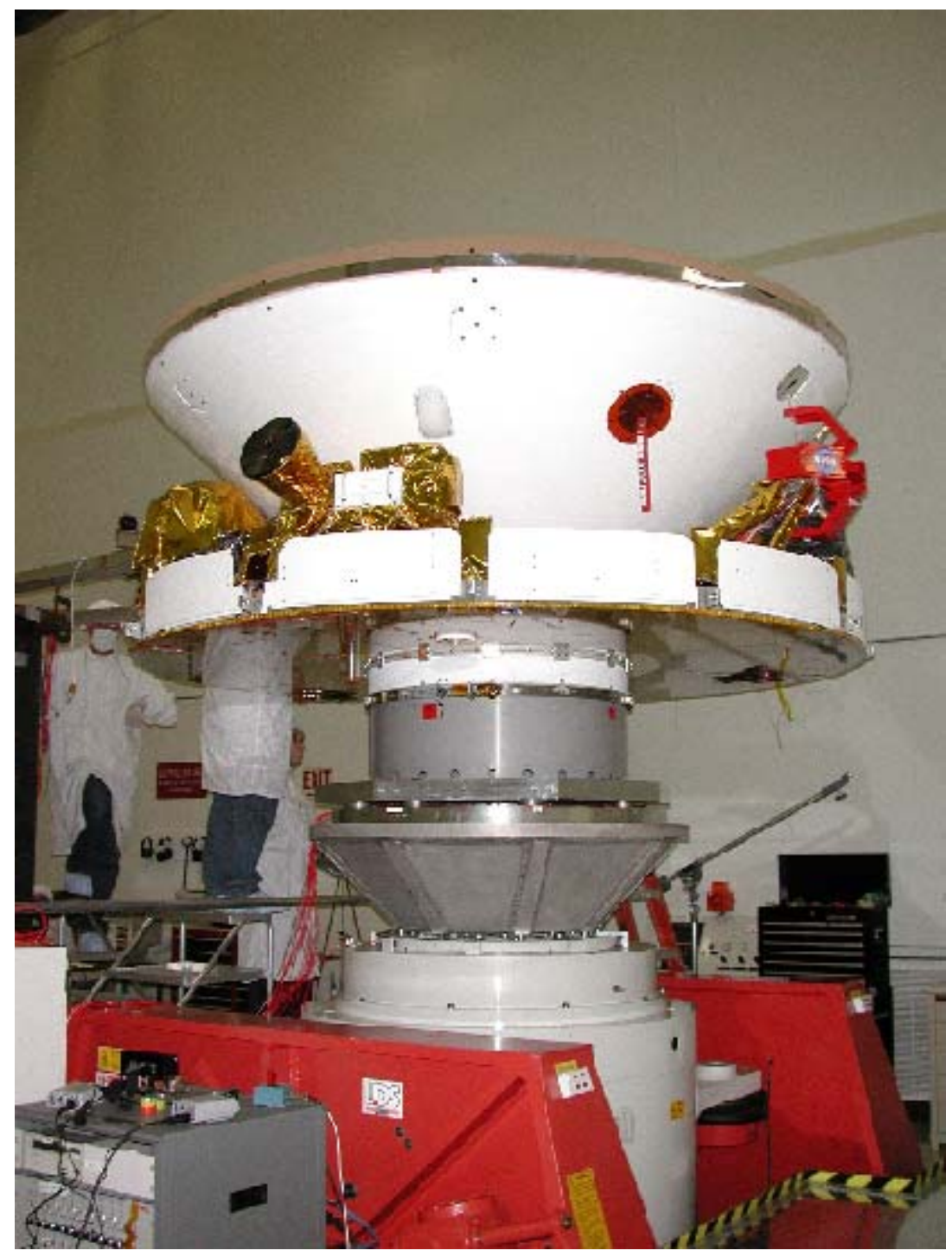




\section{Vibration Test}

JPL

- MER Flight Spacecraft during vibration testing

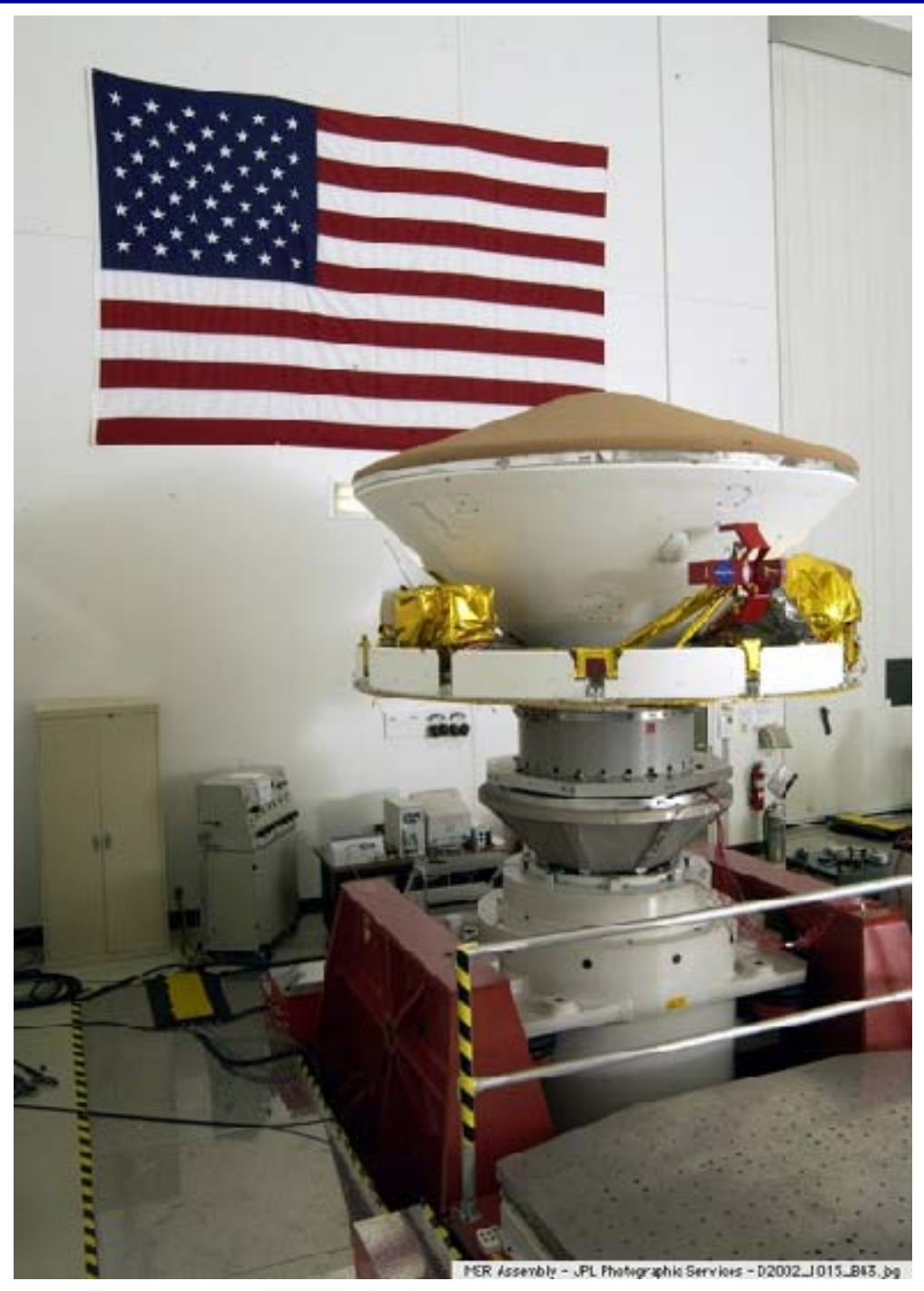




\section{Vibration Test}

$J P L$

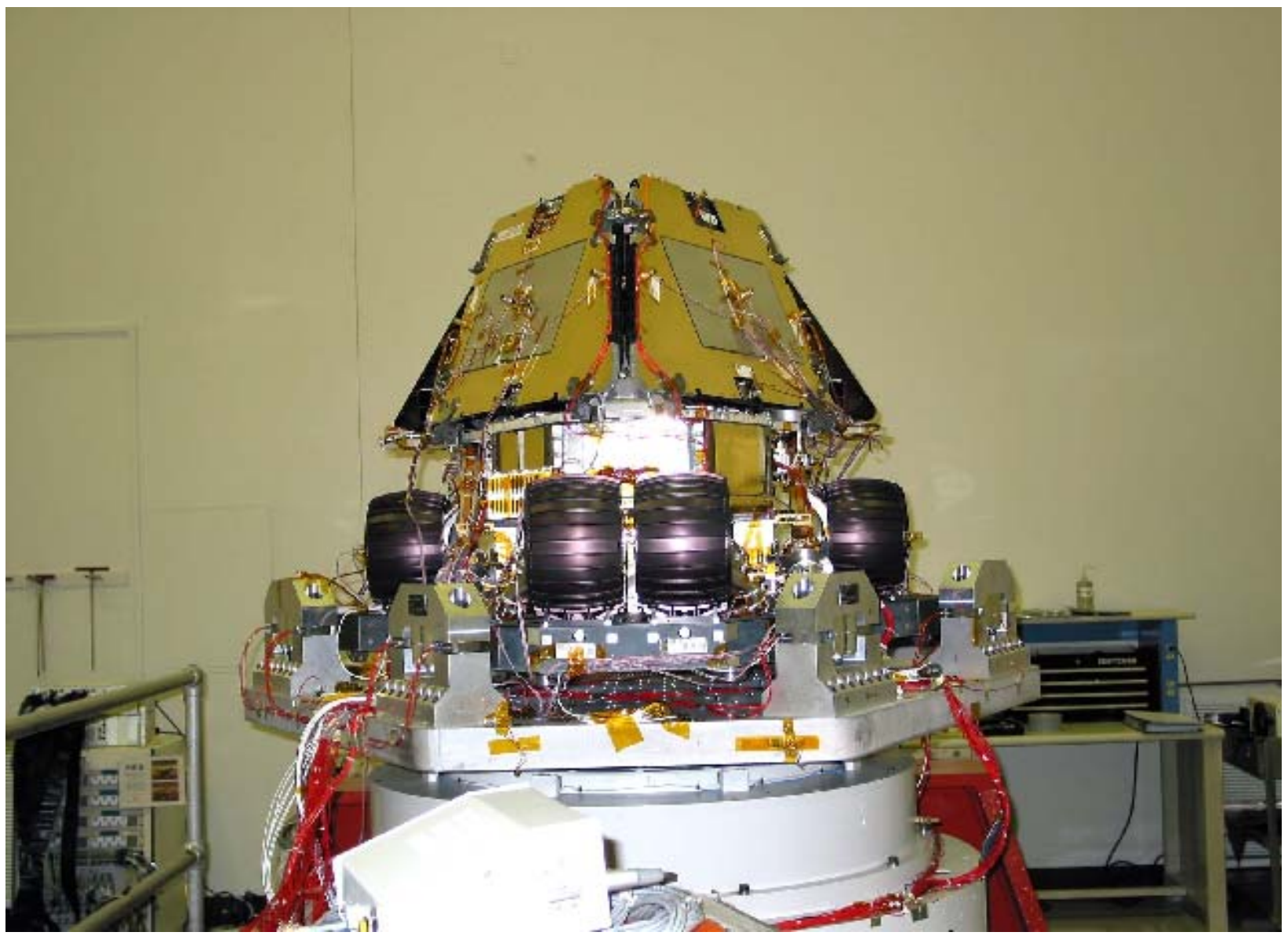

- Flight Rover during vibration and landing loads testing on the LDS 994 shaker 


\section{Acoustic Test}

- MER Flight System in the JPL Acoustic Chamber

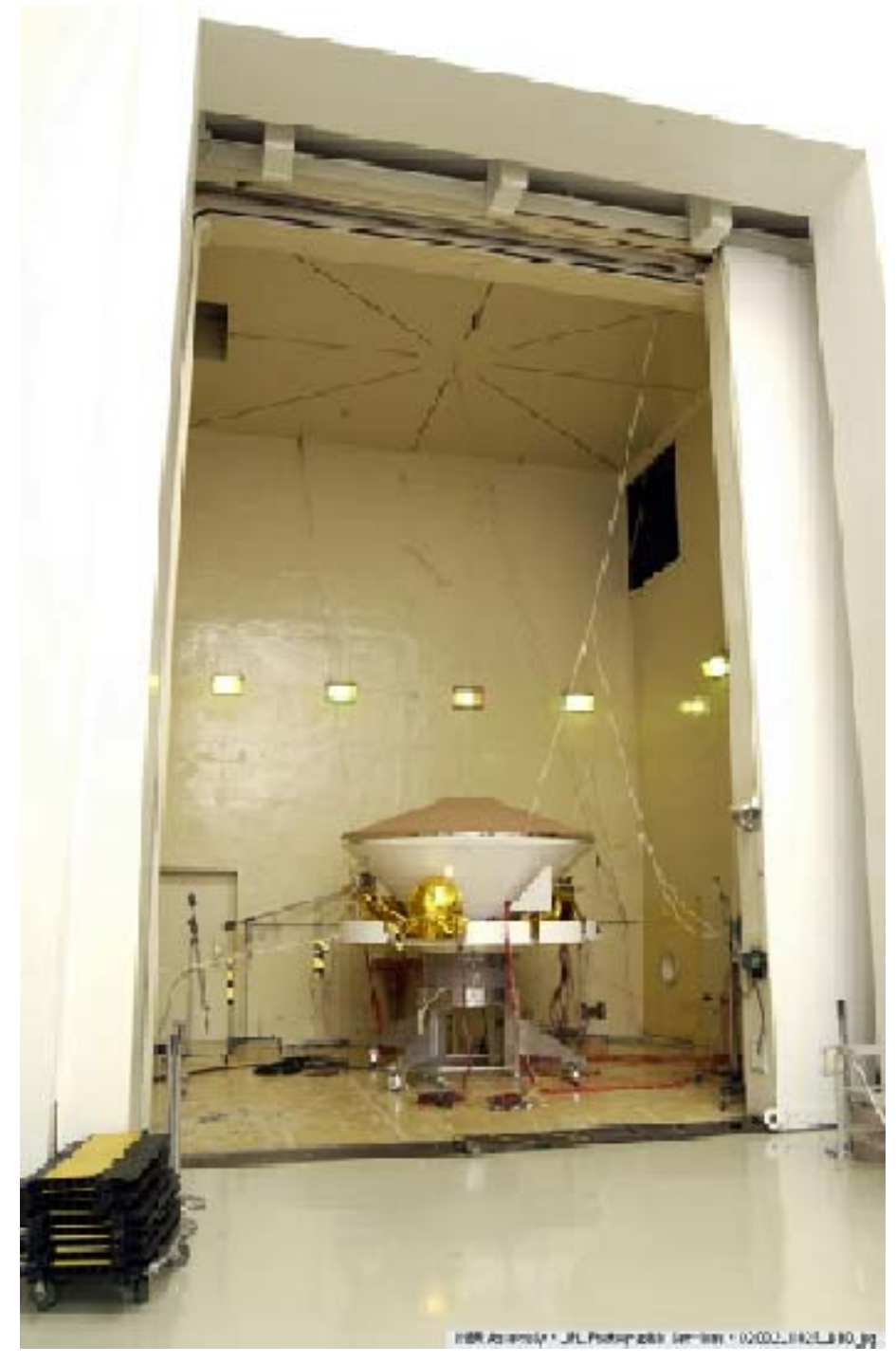




\section{Mass Properties Test JPL}

- MER Flight System during Mass Properties testing on the Lockheed

Martin spin balance machine at JPL

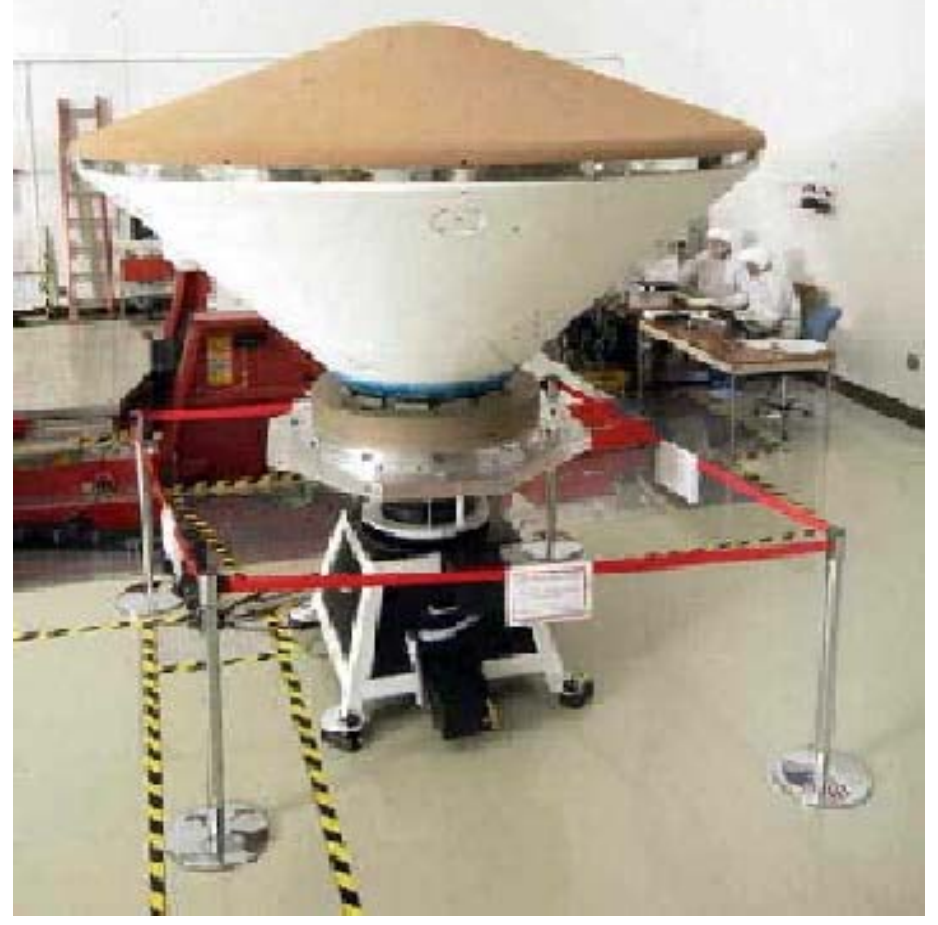




\section{Thermal Vacuum Test Program}

- Thermal vacuum testing was performed during the design and development phase, at the sub-system level and during the assembly, integration and test phase of the project

- High vacuum testing was used to simulate the cruise phase of the mission between Earth and Mars

- Vacuum testing at 8 Torr (10 millibar) in a $\mathrm{GN}_{2}$ or $\mathrm{CO}_{2}$ environment was used to simulate the landed phase of the mission on the surface of Mars 


\section{Thermal Vacuum Test Program}

- During the design phase of the MER project many thermal cycle and thermal vacuum tests were performed on the small electric motors, actuators and relays that are used to deploy the many mechanisms on the rover

- Much of this testing was done at Mars surface conditions

- During the flight acceptance test phase of the project, numerous assemblies and subsystems were tested in small thermal vacuum chambers at JPL and vendor facilities

- Mobility components, actuators, mechanisms, electronic packages, cameras and spectrometers 


\section{Thermal Vacuum Test Program}

- During the assembly, integration and test portion of the MER program both flight systems were tested in a solar-thermal-vacuum environment in the JPL 25-ft Space Simulator Facility

- 25-ft (7.7 m) diameter, 85-ft (25.7 m) high vertical cylinder

- High vacuum (10-6 Torr range)

- Chamber Walls at $-185^{\circ} \mathrm{C}$

- Solar Simulation at 1 Earth Solar Constant

- $130 \mathrm{mw} / \mathrm{cm}^{2}$

- Solar Simulation at near Mars

- $60 \mathrm{mw} / \mathrm{cm}^{2}$ 


\section{Space Simulation Test

-The JPL 25-ft Space Simulation Chamber

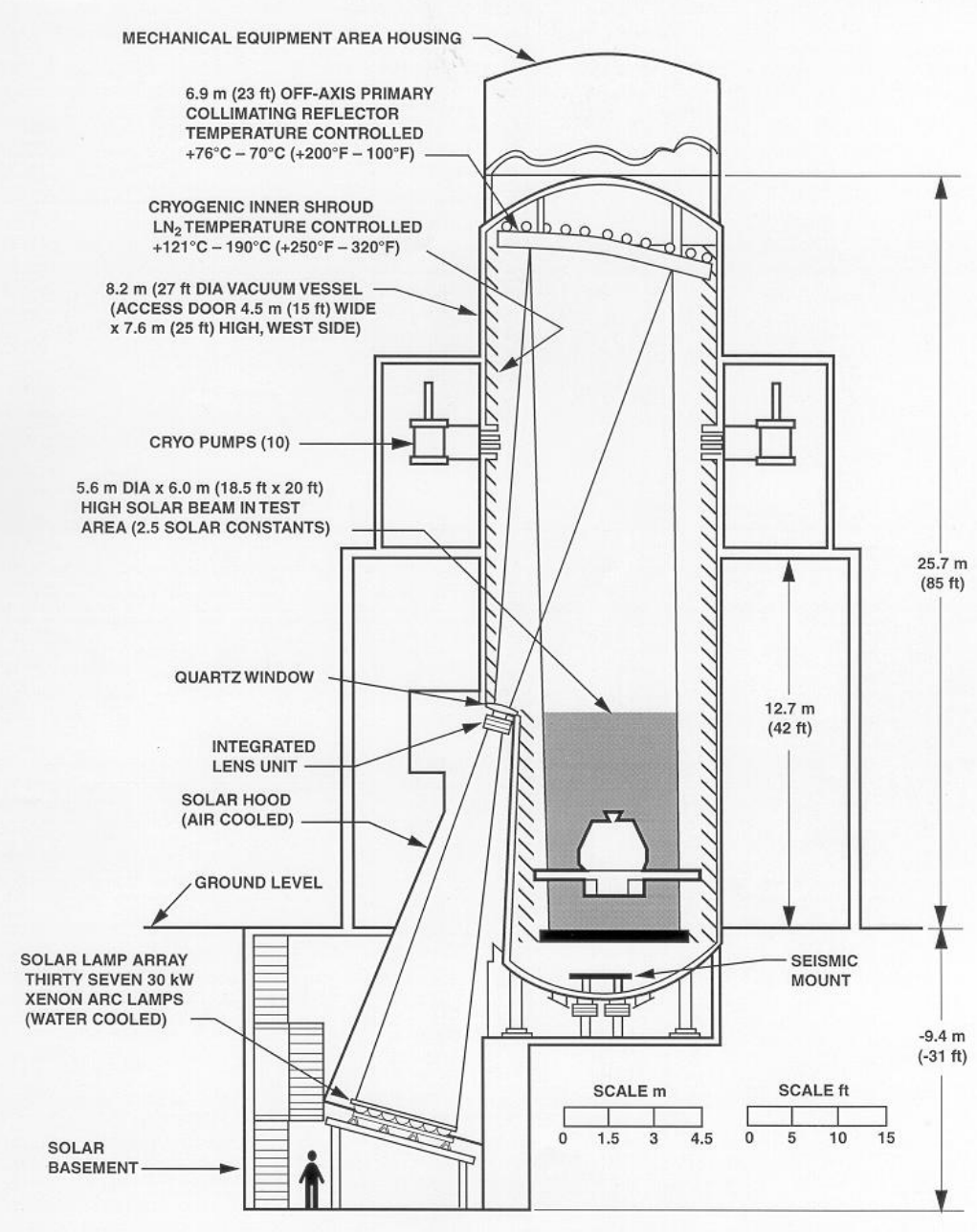

JPL 7.6 m (25 ft) SPACE SIMULATOR CROSS SECTION (LOOKING EAST) BUILDING 150 


\section{Space Simulation Test $\quad$ JPL}

- MER Flight System in the JPL 25-ft Space Simulator during preparations for SolarThermal-Vacuum testing

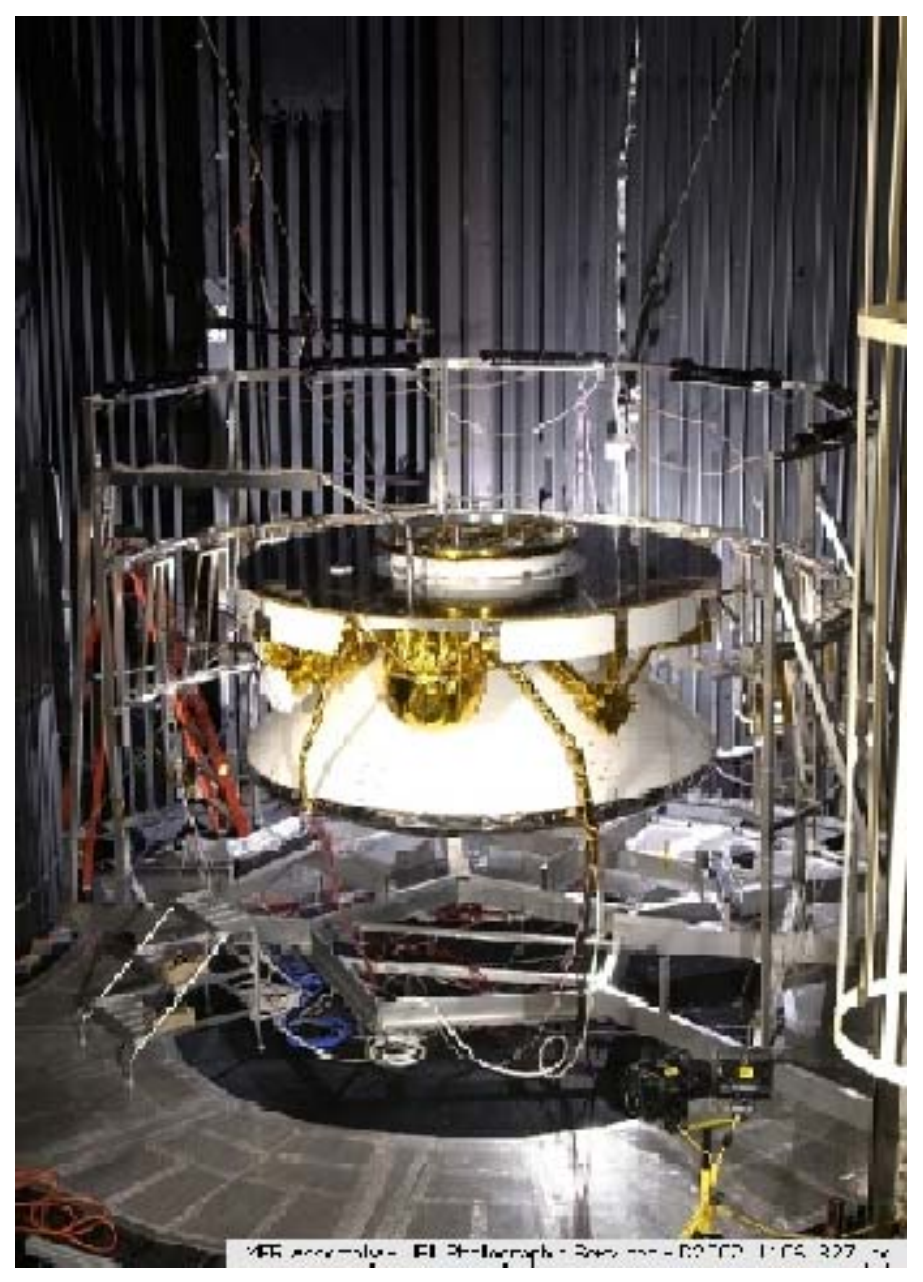




\section{Space Simulation Test \\ $J P L$}

- MER Flight Spacecraft in the JPL 25-ft Space Simulator during solar beam mapping prior to pump down for SolarThermal-Vacuum testing

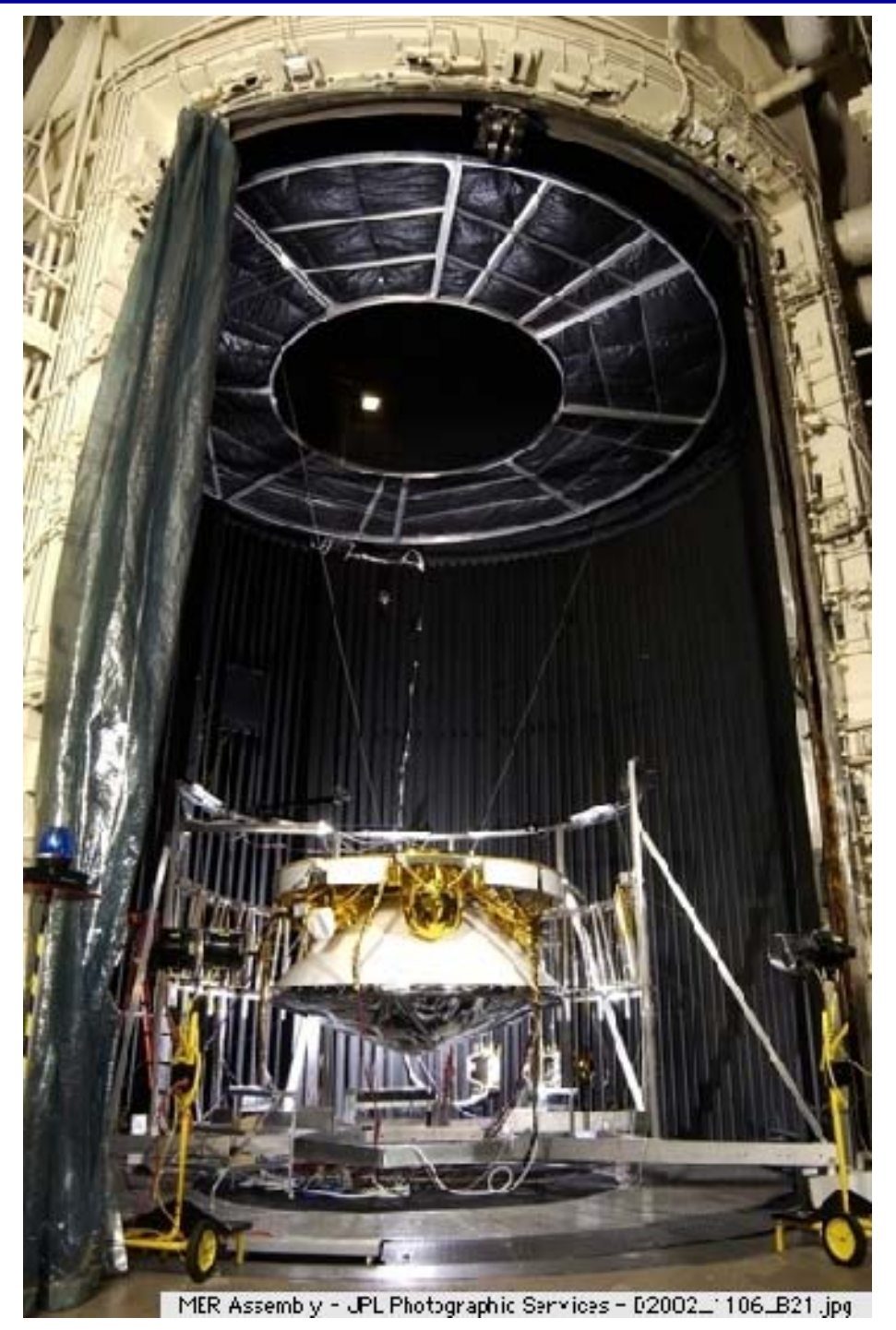




\section{Thermal Vacuum Test Program}

- Special testing was performed in the large JPL chambers to simulate the decent into the Martian atmosphere from deep space

- The purpose was to confirm the ability to communicate with the spacecraft's telecommunications system during the decent phase

- This type of "controlled re-pressurization or backfill" had never been attempted in the JPL large space simulator

- To accomplish this special test, the chamber backfill with nitrogen was halted at $1 \times 10^{-1}$ Torr and then resumed at an accurately controlled rate to reach 8 Torr in exactly 6 minutes 


\section{Space Simulation Test

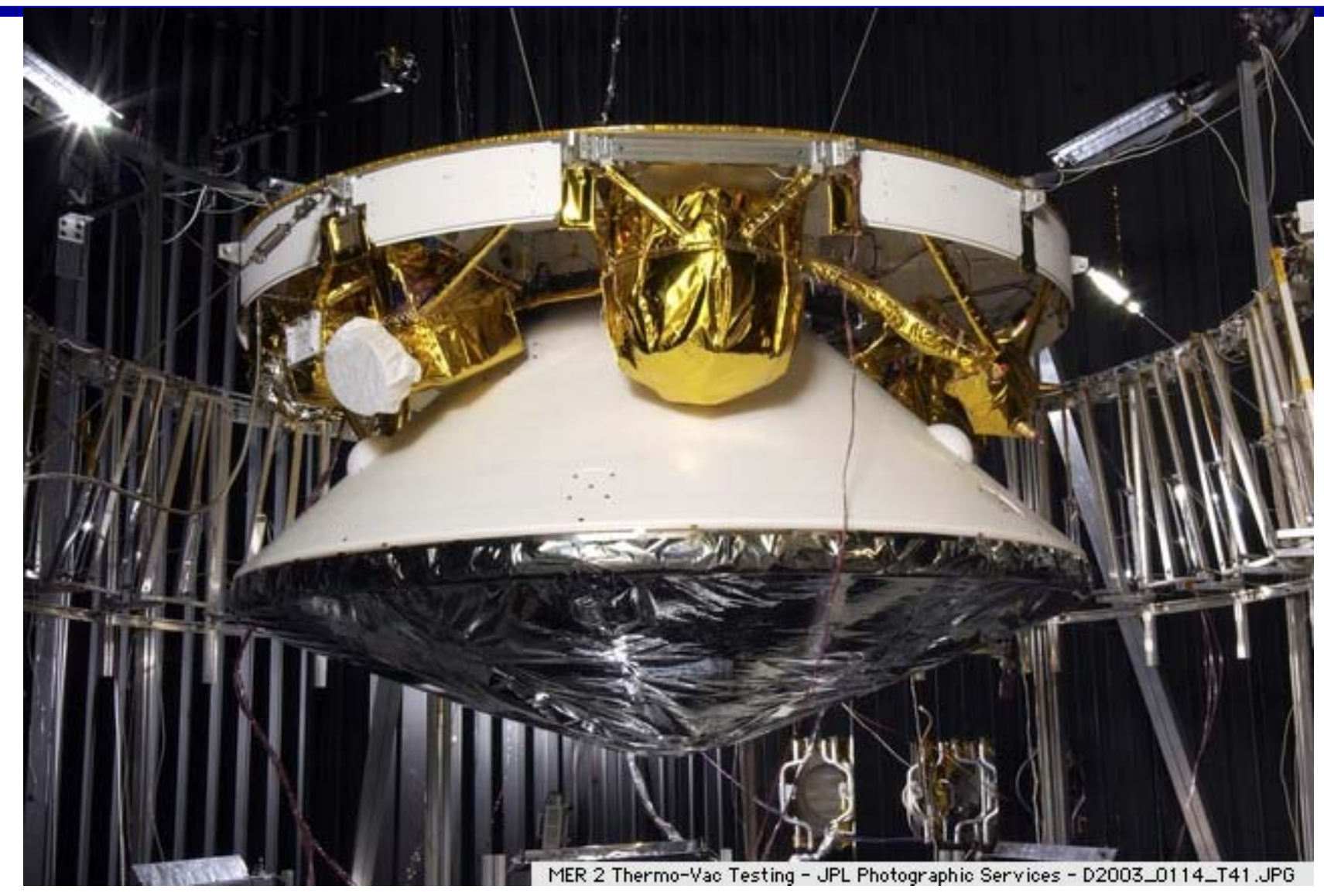

- Close-up of MER 2 Flight Spacecraft in the JPL 25-ft Space Simulator prior to pump down 


\section{Thermal Vacuum Test Program}

- Also during the assembly, integration and test portion of the MER program both flight Rovers were tested in a thermal-vacuum environment in the JPL 10-ft Space Simulator Facility

- 10-ft (3 m) diameter, 45-ft (13.7 m) vertical cylinder

- This testing consisted of the Rover in the landed configuration in a Mars environment

- Chamber pressure was maintained with nitrogen in the 8 to 10 Torr (10 millibar) range

- Temperature of the shrouds and ground plate were held at various levels between $-130^{\circ} \mathrm{C}$ and $+20^{\circ} \mathrm{C}$ to simulate Martian night and day thermal extremes 


\section{Space Simulation Test \\ $J P L$}

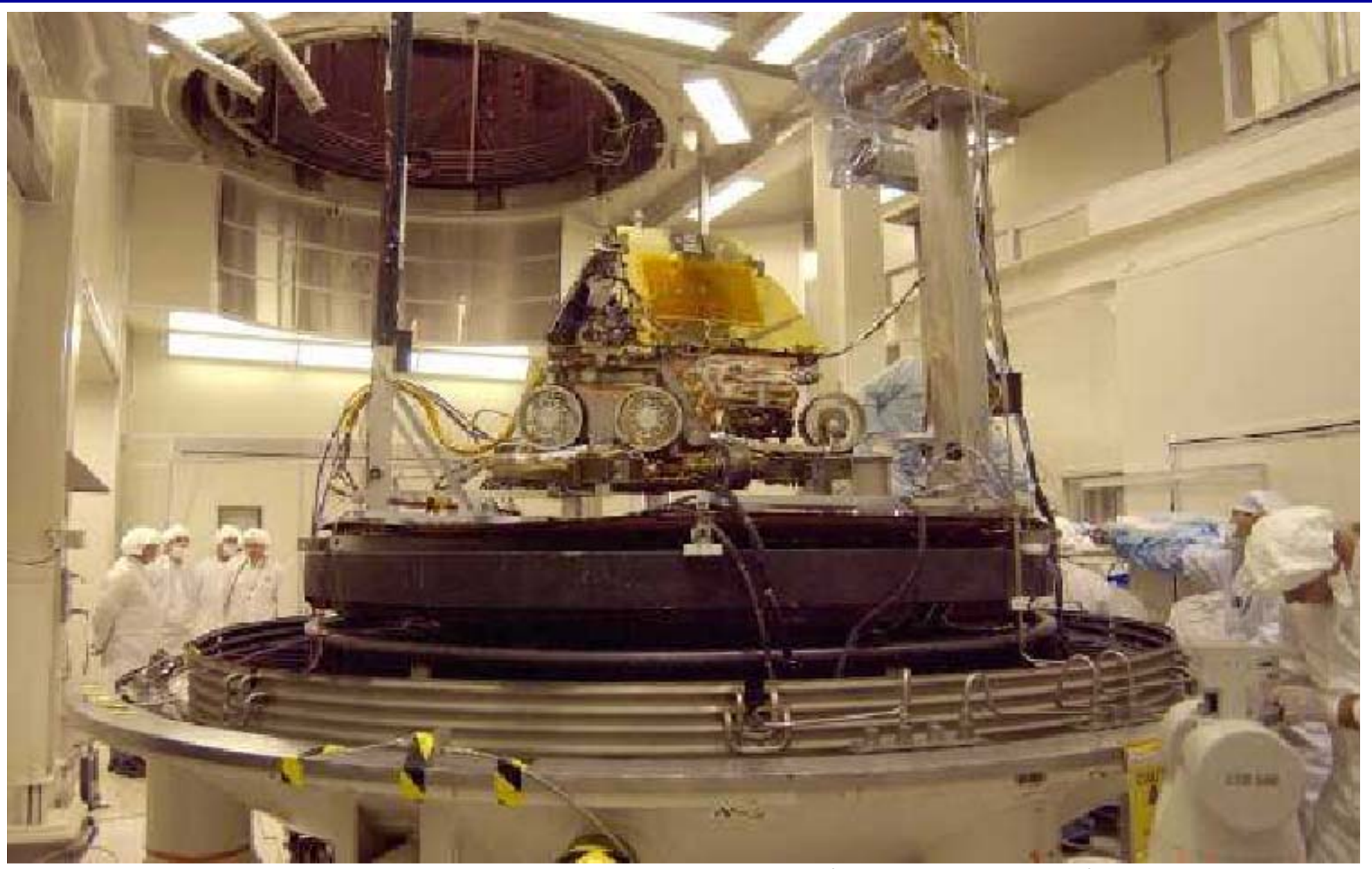

- Flight Rover being prepared for Mars surface testing in the JPL 10-ft Space Simulation chamber 


\section{Thermal Vacuum Test Program}

- During one test numerous pyrotechnic devices were fired to verify the deployment of solar arrays and mobility components in the simulated Mars surface environment

- During other test runs the Rover was placed at several different angles in relation to the ground plate to simulate different landing positions on the Martian surface to verify that the Rover could properly deploy under these adverse conditions 


\section{Space Simulation Test}

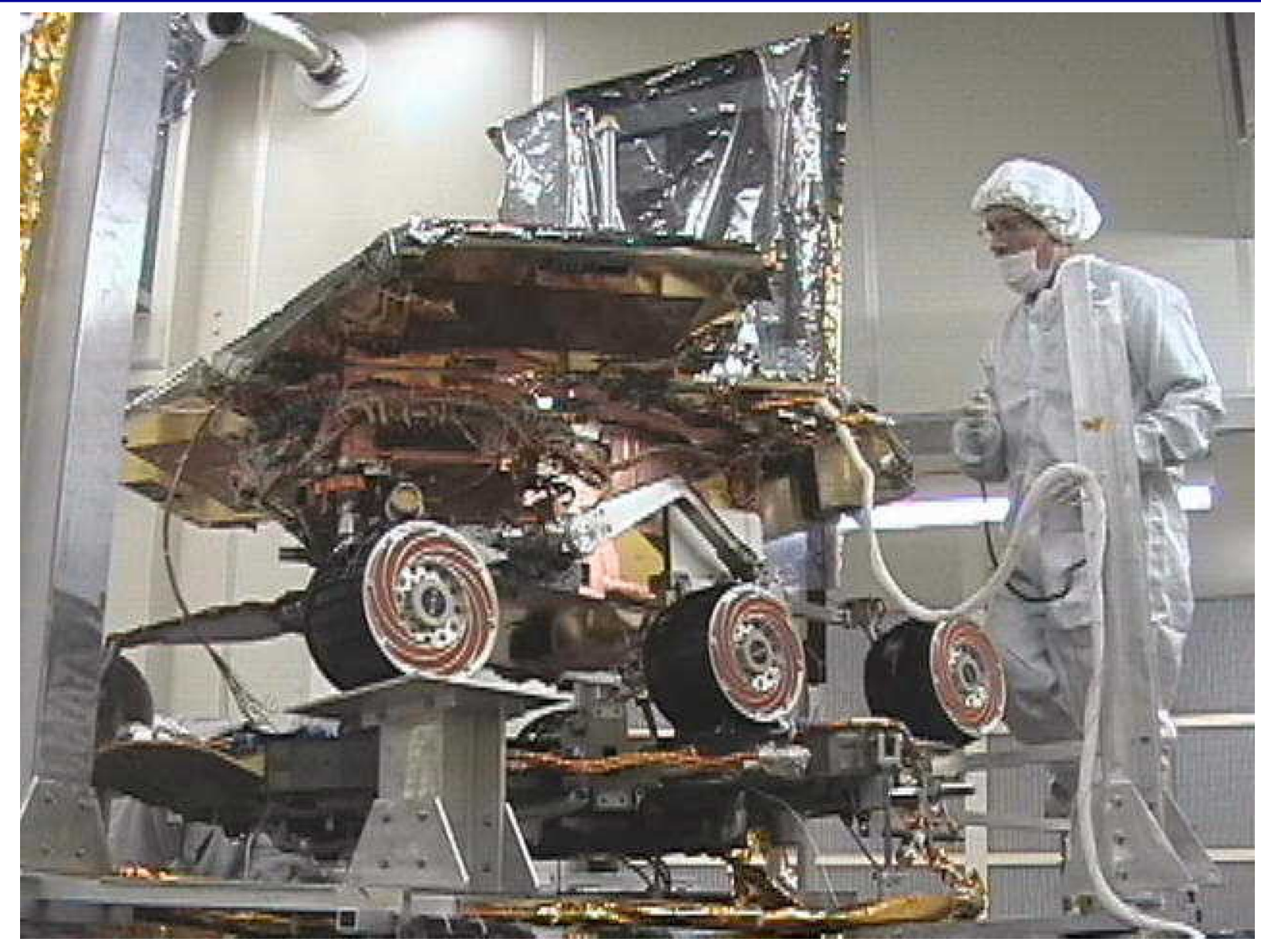

- Flight Rover after deployment during Mars surface testing in the JPL 10-ft Space Simulation chamber 


\section{"Opportunity" Landing Site JPL}

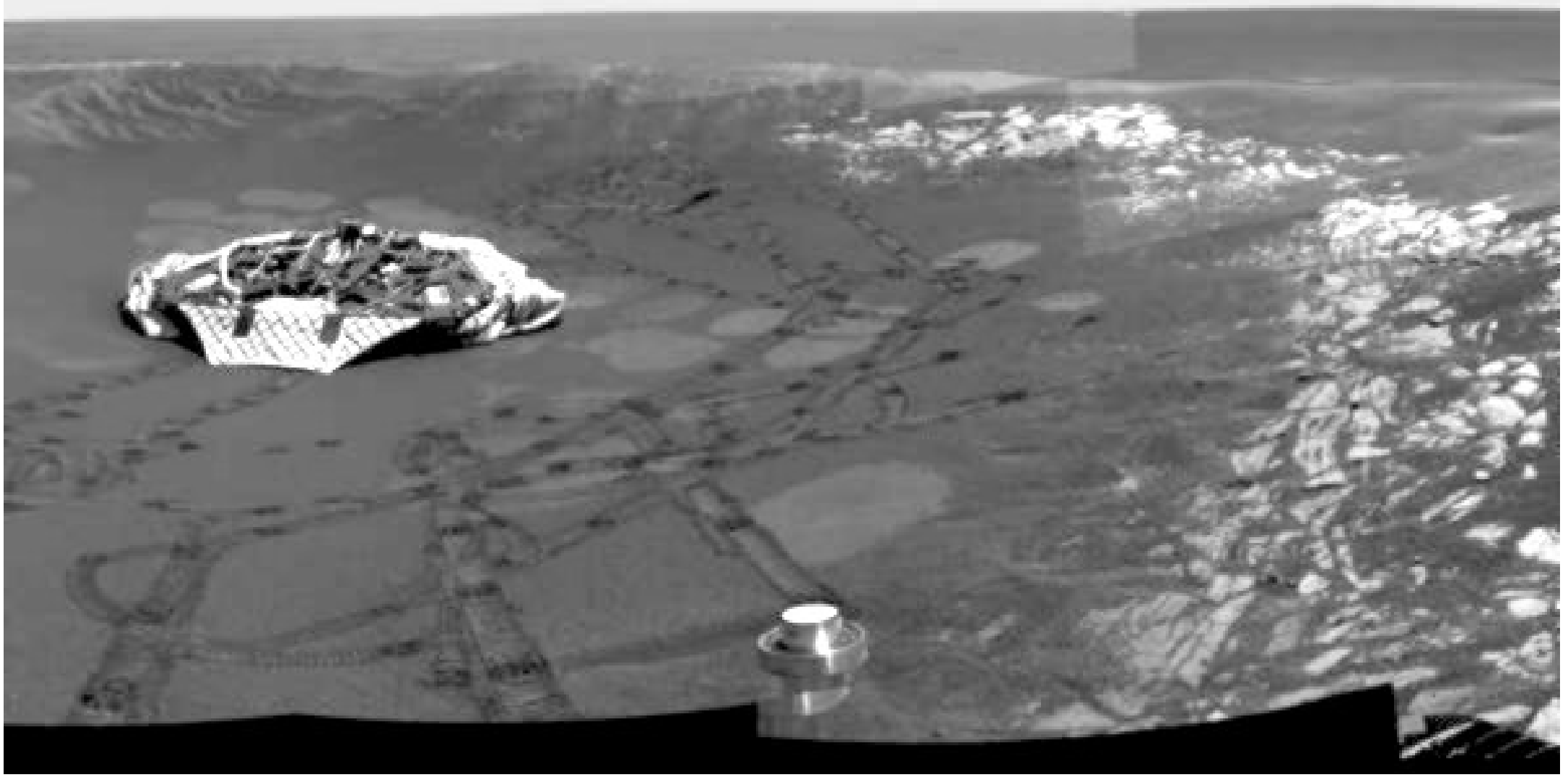




\section{Conclusions}

- The Mars Exploration Rover test campaign was successfully performed in the JPL Environmental Test Laboratory between early 2001 and the spring of 2003

- Close contact with the project management and the project's engineering staff helped in maintaining a smooth flow of testing through the ETL

- At the completion of the environmental test program, the two flight worthy spacecraft were successfully launched in the summer of 2003 